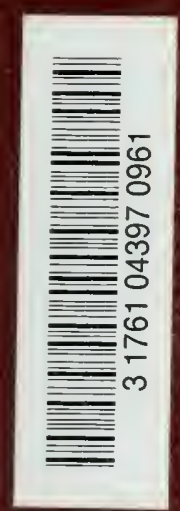

OK

495

$04 A 3$

1884

c.1

BMED 





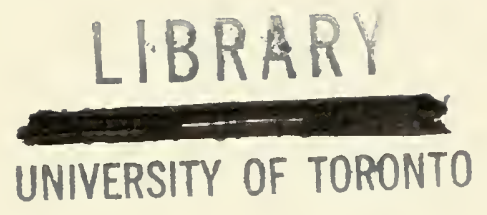



Ueber

\title{
die Anatomie des Eichenholzes.
}

\section{Inaugural-Dissertation}

zur

\section{Erlangung der Doctorwürde}

\author{
vou der
}

philosophischen Facultät

der

Albertus-Universität in Königsberg in Pr.

genehmigt

und

Dommerstag, den 10. Juli 1s8t um 12 Uhr

nebst den angefïhrten Thesen

öffentlich vertheidigt

ron

Johannes Abromeit

aus Paschleitschen.

Opponenten :

Dr. phil. Bethke. Cand. prob. Kurpiun. Stud. rer. nat. Kynast.

BERLIN.

Druck von G. Bernstein.

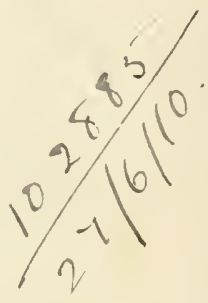

SW. Zimmer-Strasse 94. 


$$
\begin{aligned}
& 2 K \\
& 495 \\
& Q 4 A 3 \\
& 1884
\end{aligned}
$$


Seinem hochverehrten Lehrer

\section{Herrn Professor Dr. Robert Caspary,}

Director des Königl, botanischen Gartens zu Königsberg,

elirfurchtsvoll

gewidmet

vom

Verfasser. 



\section{Einleitung.}

Im Jahre 1880 erhielt Professor Caspary von Charles S. Sargent Arnold, Professor of Arboriculture in Harward College, Brookline Mass., cine sehr reichhaltige Sammlung werthvoller nordamerikanischer Holzarten, worunter sich auch Stammstücke von 23 Eichen befinden.

Auf Anrathen des Professor Caspary suchte ich den anatomischen Bau der letzteren zu erforschen, da zu erwarten stand, dass die in morphologischer Hinsicht so sehr von einander verschiedenen Arten auch im inneren Bau einige Unterschiede erkennen lassen werden. Um nun einen möglichst grossen Ueberblick zn gewinnen, war es zunächst erwünscht, das Holz recht vieler Eichenarten zu untersuchen. Auf gütige Verwendung des Professor Caspary wurde die Holzsammlung des königsberger botanischen Gartens durch Sendungen zahlreicher, höchst werthvoller und seltener Eichenarten aus den botanischen Gärten zu Berlin und St. Petersburg bereichert, so dass es mir nunmehr möglich war, den anatomischen Bau des Holzes von 55 Eichenarten zu erforschen. Gerade die Kenntniss der nordamerikanischen Hölzer ist für die Bestimmung unserer T'ertiärflora von grosser Wichtigkeit, da besonders durch die vegetabilischen Einschliisse des Bernsteins eine starke Verwandtschaft der damaligen 
preussischen Flora mit der jetzigen nordamerikanisehen bewiesen wird und es daher wahrseheinlich ist, dass unter den fossilen Laubhölzern, die sich jetzt bei uns finden und wohl vorzngsweise aus dem Tertiär stammen, auch Laubhölzer anzutreffen sind, anf die durch genaue Untersuchung der jetzt lebenden Eichenarten Licht in Betreff ihrer Verwandtschaft geworfen werden kann.

Ich habe in vorliegender Arbeit versucht, das Charakteristische im Bau des Eichenholzes festzustellen, woran hoffentlich auch fossile Stïmme nach geeigneter Behandlung erkannt werden dürften. Sehr wesentlich erleichterten meine Untersuchungen zweckmässige Präparate, die von Moeller in Wedel in Holstein für den botanisehen Garten zu Königsberg angefertigt wurden. Die Schnitte gewähren bei grosser Fläehe eine gute Uebersicht über die Anordunng der verschiedenen Zellarten und Gefässe im Stamme, jedoch wurden diese über grössere Flächen Ueberblick gebende Schnitte meinerseits durch genauere anatomische Untersuchung ergänzt.

Der Stamm der Eichen war bereits beim Beginne der mikroskopischen Erforschung des inneren Baues der Pflanzen Gegenstand anatomischer Untersuchung. Die ältesten Anatomen Malpighi, Grew und Leeuwenhock widmeten dem festen und allgemein gebrauchten Eichenholz ihre Aufmerksamkeit und entdeckten seine wesentlichsten Bestandtheile: enge und weite Gefässe, Holzspitzzellen und Markstrahlen. Doeh gelang es ihnen noch nicht, die parenchymatische Natur der Holzstumpfzellen den anderen Zellen gegenüber klar zu legen. Zwar bildet sie Malpighi') vom Eichenhol\% auf dem radialen Schnitt ab, liisst sie jerloch auf der Abbildung des Querschnittes fort. N. Grew ${ }^{2}$ ) lïsst die Stumpfzellen auf der Zeichnung eines Quersehnitts von Quereus, Tab. III. Fig. 7, fort, deutet sie jedoch auf Tab. 33 Fig. 2 an und bezeichnet sie mit den Buchstaben SZT. In der Figurenerklïrung bemerkt er hierzu: „Probably one sort of sap-ressels heretofore in the barque". Nachdem

1) Malpighi: Anatome plantarum, Tom. I, p. 8, Fig. 21 zwischen DD der Tab. VI.

2) Nehemias Grew: The anatomy of plants, 1682. 
Leeuwenhoek ${ }^{1}$ ) an den grossen Gefässen der Eiche die gehöften Poren, ohne sie richtig zu denten, entdeckt und Moldenhawer ${ }^{2}$ ) die Holzstumpfzellen den Spitzzellen gegenüber genügend charakterisirt hatte, wurde die Kenntniss des anatomischen Baues des Eichenholzes bis auf unsere Zeit nicht wesentlich gefördert. Zwar weist $\mathrm{Hill}^{3}$ ) schon 1770 darauf hin, dass bei immergrünen Eichen die Gefässe im Stamme eine radiale Anordnung erkennen liessen, doch hat er seine Untersuchungen an zu jungen, noch nicht ausgewachsenen Stämmen gemacht. Auch sind seine Angaben bei Anwendung von volksthümlichen Namen für verschiedene Eichenarten zu unbestimmt, als dass sie der weiteren Forschung einen sicheren Grund hätten geben köunen. In jungen, 1-6jährigen Eichenstämmen sind die Gefïsse und Holzspitzzellen stets radial angeordnet. Erst im älteren Stamm nehmen die Gefässe eine beständige Gestalt an und befinden sich dann in bestimmter, gewissen Arten charakteristischer Anordnung' unter den übrigen Bestandtheilen des Holzes. Daher eignet sich das später eutstandene, secundäre Holz zur Unterscheidung von Holzarten nach anatomischen Merkmalen am besten. -

Es blieb Hugo von $\mathrm{Hohl}^{4}$ ) vorbehalten, im Eichenholz zweierlei Arten von Spitzzellen zu entdecken, nämlich solche, die keine "Tüpfel" besitzen und andere, welche meist in der Nähe der Gefässe befindlich „Hoftüpfel" aufzuweisen liaben. Diese Entdeckung wurde später von Theodor Hartig $^{5}$ ) bestätigt, denn dessen "linsenräumig getüpfelte Holzfaser" ist nichts anderes als die gehöft geporte Holzspitzzelle. Letzterer weist zugleich mit Bestimmtheit auf die Verschiedenheit in der Grösse und Anordnung der Gefässe des Eichenholzes hin und verwendet diese Verhältnisse zur Charakteristik des Stammes von Quercus. Er hebt hervor die Anordnung der Holzstumpfzellen („Schichtzellen“) zu tangentialen

1) Leentenhoek: Opera omnia, Tom. I p. 12, Fig. 4 u. 7; Tom. III p. 288, Fig. 19, Tom. III p. 464, Fig. 10 u. 11.

2) Moldenhawer: Beyträge zur Anatomie der Pflanzen, 1812.

3) John Hill: The construction of timber from its early growth. London 1770 , p. 169.

4) v. Mohl: Ueber die Poren des Pflanzenzellgewebes, 1828, p. 23.

5) T'h. Hartig: Vollständige Naturgeschichte der forstlichen Culturpflanzen Deutschlands, 1851, p. 144. 
Streifen und erkennt riehtig, dass sie aus "Cambialfasern" durch Quertheilung derselben entstehen.

Carl Saniol) macht auf vier verschiedene Arten von Markstrahlen des Eichenstammes aufmerksam, stellt jedoch für Quercus Ilex breite primäre Markstrahlen in Abrede, eine Beobachtung, die ich am Stamm derselben Eichenart (entstammend dem Königl. botanischen Garten zu Berlin) nicht bestätigt gefunden habe. Dagegen betont er die nahezu gleiche Grösse und radiale Anordnung der Gefüsse bei erwähnter Eiche.

Es berïcksichtigt ferner (Viesner ${ }^{2}$ ) den anatomischen Bau von Quereus pedunculata Ehrh., Q. sessiliflora Sm., Q. Cerris L. und Q. pubescens Willd. Seine Beobachtungen sind lïckenhaft und erstreeken sich nur auf Qnerschnitte. Es kann nicht gerechtfertigt werden, dass er auf dem Querschnitt von Q. Cerris die radial angeordneten Züge kleiner Gefässe, die man schon mit blossem Auge erkennen kann, nicht abbildet.

In nenester Zeit zogen J. Möller ${ }^{3}$ ) und Paul Sanio4) den Eichenstamm nochmals zur wäheren Untersuchung. Ersterer giebt eine genauere Beschreibung der Bestandtheile des secundären Holzes von Quercus Cerris und fïgt dabei bereits Bekanutem nichts wesentlich Neues hinzu. P. Sanio berüeksichtigt bei Bearbeitung des Stammes von Quereus pedunculata das Holz der Markscheide und entdeckt die getheilte Holzspitzzelle, welche mit der gefïcherten Libriformfaser C. Sanio's identisch ist.

Es hat bisher kein Anatom den Bau des Holzes sehr vieler Arten dieser grossen Gattung nïher zu erforsehen gesueht, um die bereits aufgestellten Diagnosen des Eichenholzes zu prüfen und sichere Merkmale für Arten oder Artgruppen zu gewinnen. Das, was die erwähnten Forscher von dem Ban einiger Stämme aussagten, bedurfte noch einer weiteren Bestätigung durch ausgedelntere Untersuchungen. Ich will jedoch damit keineswegs behaupten, dass meine Arbeit bereits den Abschluss der anatomischen Erfor-

1) C. Sanio: Botanische Zeitung Jahrg. 1863, p. 404 u. $40 \Omega$.

2) Wiesner: Rohstoffe des Pflanzenreichs, 1873, p. 607 .

3) Iöller: Denkschriften der kaiserl. Akademie der Wissenschaften zu Wien, 1876, 36. Bd., mathem.-physikal. Klasse, p. 297.

P. Sanio: Programm der Realschule auf der Burg. Königsberg 1877, p. 6. 
schung bilde, sondern behalte es mir vor, über diesen Gegenstand noch weitere Ergebnisse zu sammeln.

Die Holzanatomie bietet rüstigen Arbeitern ein weites Feld für emsige Thätigkeit, und erst dann werden vollkommen sichere Resultate erzielt werden, wenn möglichst viel Material von einheitlichen Gesichtspunkten aus gut untersucht sein wird. Es war durehaus nothwendig, gewisse unveränderliche Grössen- und Lagerungsverlülthisse ron Ilolzbestandtheilen aufzusuchen, um dieselben zur Gruppirung der versehiedenen Eichenlölzer zu verwerthen. Zunächst eignen sich Anordnung und Baubeschaffenheit der Gefässe zur Bildung grösserer Artgruppen, und die Dimensionen der Narkstrahlen sowie die Art ihrer Vertheilung im Stamme bieten Merkmale dar, die in einigen Fällen sogar die Eichenart erkennen lassen. Doeh darf auf dieses letztere Merkmal nicht unbedingt Gewicht gelegt werden, da bereits Beobachtungen Jehren, dass die Ausdehnung und Anordnung der grossen Markstrahlen einige Schwankungen zeigen. Es müssten zahlreiche Cntersuchungen versehiedener Stämme einer und derselben Art angestellt werden zum Zweek der Begrenzung von Abweiclungen im Bau und Anordnung der Markstrahlen. Das Holz der meisten ron mir untersuchten Eichen zeigt recht zahlreiche nahestehende breite Markstrahlen, die stets mit blossem Auge wahrgenommen werden können. Nur bei Quercus rugosa Née ${ }^{1}$ ), Q. chrysolepis., Q. glabra Thbg., Q. oblongifolia Torr., Q. cuspidata Thbg. ${ }^{2}$ ) und ganz besonders auffallend bei Q. dilatata Lindl., einer Eiche rom Himalaya, bemerkte ich eine wesentliche Abänderung im Bau derselben. Die breiten Markstrahlen verschwinden hier gegen die Peripherie des Stammes, indem sie von recht zahlreichen Holzspitz- und Stumpfzellen, seltener von Gefüssen durchsetzt werden, was besonders auf dem tangentialen Schnitt gut zu erkennen ist. Bei Quereus dilatata erscheint der ganze breite Harkstralıl unter dem Mikroskop in vicle kleine Markstrahlen aufgelöst. Es sind dies die ,aussetzenden Markstrahlen“ Hartig's ${ }^{3}$ ), welehe

1) Bei dieser und Q. Ilex sind sie von Spitzzellen stark durchsetzt.

2) Bei diesen Arten treten einige Jarkstrahlen an der Peripherie des Stammes nicht heraus.

3) Botanische Zeitung 1859, p. 94. 
Wiesner ${ }^{1}$ ) "scheinbar deutliche" nennt und sie nur für Tectonia grandis L. fil., Alnus, Carpinus und Corylus angiebt.

Sehr eigenthümlich ist auch das öftere Vorkommen von Krystallen des oxalsauren $\mathrm{Kalks}^{2}$ ), die meines Wissens nur von $\mathrm{Schacht}{ }^{3}$ ) für Eichenholz und zwar im Parenchym von Quercus Suber constatirt wurden. Ich fand sie in Holzstumpf- und Markstrahlzellen vieler Eichen und nur in dem Holz folgender Arten habe ich sie nicht finden kömnen. Es sind dies: Quercus pedunculata, Thomasii, sessiliflora, macranthera, grosseserrata, lobata, Prinus, aquatica, Catesbaei, imbricaria, chrysolepis, glauca, gilva, glabra und cuspidata. Bei Quercus virens Ait. und hypoleuca Engelm. konnte ich sie nur in den Stumpfzellen entrecken, doch dürften sie wohl auch hier in den Markstrahlzellen noch vorkommen.

Th. Hartig ${ }^{4}$ ) scheint im Eichenholz Aehnliches gesehen zu haben, doch giebt er keinen genauen Aufschluss ïber die chemische Natur der Krystalle und neunt auch keine bestimmte Eichenart, deren Holzzellen dergleichen enthalten könnten. Ich bemerkte die erwähnten Krystallkörper in der Nähe Stärke führender Stumpfallen. Im Holz des jungen Stammes von Quercus Fordii Hort. konnte ich fünf vertical über einander liegende, aus einer cambialen Zelle durch Quertheilung entstandene Stumpfzellen beobachten, von denen jo zwei Endzellen Stärkckörner und die mittlere vier Krystalle enthielten. Die Stärkekörner wurden wie gewöhnlich durch Jodzusatz blau, während die Krystalle hell blieben; auch zeigten letztere weder gebogene abgerundete Kanten wie die Krystalloide, noch zersetzten sie sich in der Essigsäure, sondern lösten sich in Salz- oder Salpetersäure, ohne aufzubrausen. Dieses Verhalten zu den Reagentien nöthigte mich, sie für Krystallformen des oxalsauren Kalks zu halten, der ja für einige Hölzer und für die Rinde von Quercus pedunculata

1) l. c. p. 522 u. 523 .

2) Fig. 1a, b, c, d. Nach Souchay und Lenssen (Annalen der Chemie und Pharmacie, Bd. 100 p. 311 ) haben die klinorhombischen Formen die Zusammensetzung:

$\left.\begin{array}{l}\mathrm{CaO} \\ \mathrm{CaO}\end{array}\right\} \mathrm{C}_{4} \mathrm{O}_{6}+2 \mathrm{aq}$, die quadratischen $\left.\begin{array}{l}\mathrm{CaO} \\ \mathrm{CaO}\end{array}\right\} \mathrm{C}_{4} \mathrm{O}_{6}+6 \mathrm{aq}$.

3) Schacht: Der Baum, p. 193

4) Th. Hartig: Anatomie und Physiologie der Holzpflanzen, 1878, p. 122. 
schon von C. Saniol) nachgewiesen wurde. Auf meine Bitte hatte Herr Professor Bauer die Güte, einige Copien dieser Krystalle in Augenschein zu nehmen und sein massgebendes Urtheil dahin zu äussern, dass die copirten Krystallkörper im Allgemeinen von den monoklinen Krystallen des oxalsauren Kalks, wie sie von Holzner ${ }^{2}$ ) beschrieben und abgebildet wurden, nicht verschieden sein dürften, aber wegen ihrer Kleinheit (die Krystalle sind 0,017-0,020 $\mathrm{mm}$ lang, wenigstens in der Mehrzahl der Fälle) keine oder doch nur eine selu zeitraubende krystallonomische Untersuchung zuliessen, ohne welche man über die systematische Stellung der erwähnten Krystalle nichts mit Bestimmtheit aussagen könne. Für das freundliche Entgegenkommen des Herm Professor Bauer bringe ich hier pflichtschuldigst meinen besten Dank.

\section{Die Bestandtheile des Eichenholzes im Allgemeinen.}

Am besten treten die wesentlichsten Grundbestandtheile des Ilolzes auf Querschnitten hervor, und will man die einzelnen Zellen einer genauen Untersuchung unterwerfen, so empfiehlt es sich, das Holz in wässeriger Chromsäurelösung oder durch Kochen in der Schultze'schen Mischung zu maceriren. Ich behandelte das Eichenholz mit Chromsäurelösung, weil mir diese bequemer schien und eben dieselben Resultate ergab wie die beim Kochen schädliche Dämpfe entwickelnde Schultze'sche Mischung. -

Zunächst will ich die Zellen, wie sie dem Ange des Beobachters in Verbande als fester Holzkörper erscheinen, berücksichtigen und die durch Vaceration gefundenen Ergebnisse theils hier schon bei Beschreibung einzelner Zellen, theils später bei Charakterisirung der Hölzer verwenden.

1) Monatsberichte der Berliner Akademie vom April 1857, p. 252. Linnaea 1857, 29. Bd. p. 127. - J. Möller in den Denkschriften der k. k. Akademie zu Wien. Mathem.-physik. Classe 1876, p. 371 и. 375.

2) Holzner: Flora 1864, p. 273. 
Nacht man einen Querschuitt durch den Eichenstamm, so wird man in der Mitte desselben einen braungelben oder braunrothen fünfstrahligen Fleck bemerken, der rom querdurchschnittenen Mark herrührt. Von dliesem gehen in radialer Richtung gelbliche oder braunrothe breite Markstrahlen bis zur Peripherie des Stammes. Es sind dieses die primären breiten Markstrahlen, welche erst von Schacht ${ }^{1}$ ) erkannt und benanut wurden. Zwischen den soeben erwähnten, kann man ausserdem noch andere breite Markstrahlen bemerken, die zwar bis zur Peripherie des Stammes reichen, aber nicht in das Mark münden. Schacht hat diese Markstrahlen secundäre genannt, weil sie später als die primären entstanden. Genau dieselbeu Verhältnisse lassen sich bei den schmalen oder kleinen Markstrahlen nachweisen. Letztere werden jedoch durch die Ausdehnung der Gefässe beim Wachsthum zur Seite gedrängt, verlaufen aber hinter den Gefässen durch die Grundmasse des Holzes genau radial. Nur bei einigen Eichenhölzern sind diese schmalen Markstrahlen mit blossem Auge zu erkennen. Ich sah sie schon sogar auf weniger guten Querschnitten bei Quercus rugosa zu 30-39 zwischen zwei etwa $3 \mathrm{~mm}$ von einander abstehenden breiten Markstrahlen. Dagegen zählte ich bei Quercus coccinea etwa 8 schmale Markstrahlen zwischen zwei $1,5 \mathrm{~mm}^{2}$ ) abstehenden breiten Strahlen. Deutlich waren sie meinem unbewaffneten Auge bei Quercus Thomasii, iberica, lyrata, oblongifolia, virens, tinctoria, rubra, lobata und glandulifera. Mit dem Nikroskop erkennt man, dass die Spitzzellen die Form der Markstrahlen durch starken seitlichen Druck wesentlich modificiren können. Seltener kommen solche Markstrahlen vor, welche, vom Marke ausgehend, die Peripherie des Stammes nicht erreichen. Ich machte bereits in der Einleitung auf dieselben aufmerksam. Die Individualitüt der breiten Markstrahlen geht bei Quercus dilatata Lindl. völlig verloren. Man sieht unter dem Mikroskop, dass die tangential durch Holzzellen und Gefässe getrennten, radial verlaufenden Markstrahlen von 2-3 Zellen horizontal zusammengesetzt, dennoch zu einer Gruppe gehören, die einem breiten Markstrahl entspricht. Der Tangentialschnitt macht denselben Eindruck und der

1) Schacht: Anatomie u. Physiologie der Giewächse, Bd. II. p. 49.

2) tangential. 
radiale Schnitt zeigt keine "Spiegel", die ich bei allen Eichen doch sonst vorfand.

Am dichtesten und breitesten $(0,5-1 \mathrm{~mm}$ horizontal) fand ich die Narkstrahlen in den Stämmen von Quereus Cerris, serrata, rugosa, nigra, palustris, pancilammellosa, glabra, thalassica, Burgeri, oblongifolia, virens, Wislizeni, Phellos und imbricaria. Breite, horizontal mehr als $5 \mathrm{~mm}$ abstehende Narkstrahlen kommen vor bei Quercus rubra, Catesbaei und bicolor. Dasselbe Verhältniss soll nach Wiesner ${ }^{1}$ ) bei Quereus sessiliflora obwalten. Am spärlichsten sind sie aber im Stamme von Quercus cuspidata Thbg. zu finden, wo sie sowohl vertical als auch horizontal $1-2 \mathrm{~cm}$ entfernt den Holzcylinder radial durchsetzen. Auf vielen Querschnitten waren keine breite Markstrahlen zu bemerken, so dass ich anfangs vermuthete, diese Eiche würde dieselben überhaupt entbehren. Nach längerem Suchen stiess ich endlich auf breite Markstrahlen, und bei vorsichtiger Behandlung des bereits morschen Holzes gelang es mir, alle sonst bei Eichen beobachteten Modificationen der Markstrahlen zu entdecken. Doch sind die meisten Markstrahlen secundär, die wenigsten primär und „aussetzend“. Betrachtet man den von der Rinde entblössten längsstreifigen Stamm von der Seite, so bemerkt man an seiner Oberfläche etwa 2--5 $\mathrm{mm}$ lange und $0,5-1 \mathrm{~mm}$ breite vertical gestreckte Grübchen mit rundlichen Rändern. Dieses sind die Ausmündungsstellen breiter Markstrahlen, und man wird letztere stets treffen, wenn man, dieses Merkmal beaclitend, durch den Stamm Schnitte macht. Es wäre sehr interessant, zu erfahren, ob solche Eigenthümlichkeiten in Stammbau bei allen asiatischen Eichen der Abtheilung Chlanydobalanus Endl., zu welcher auch Quercus cuspidata gehört, anzutreffen sind. Brandis²) bemerkt allerdings bei Erwähnung der zu Chlamydobalanus gehörigen Quercus lancifolia Roxb.: „A species differing from most other oaks by a ruminate albumen and by the structure of the wood, which has very fine medullary rays", doch bedarf diese Bemerkung noch einer weiteren Bestïtigung, da breite Markstrahlen

1) 1. c. p. 605 .

2) Brandis: The forest Flora of North-West and Central-India, London 1874, p. 489. 
nur selten ${ }^{1}$ ) zu sein brauchen, um bei weniger sorgfältig angestellten Untersuchungen für fehlend erklärt zu werden. - Meine Forschungen crgeben, dass in allen von mir untersuchten Eichenstäınmen sowohl breite als auch schmale Markstrahlen vorkommen, woran das Iolz der Gattung Quercus von den verwandten Gattungen Castanopsis und Castanea, deren Stämme nur schnnale, 1-2 Zellen ${ }^{2}$ ) breite Markstrahlen besitzen, leicht unterschieden werden kann.

Gewöhnlich sind die Zellen der Markstrahlen radial gestreckt, doch kommen sie auch in nahezu kubischer Form vor in noch jugendlichen Stämmen hin und wieder und fast regelmässig am Schluss des Jahresringes im Ierbstholz ${ }^{3}$ ). Ihre Querwände stehen nur bei den in der Mittellinie des Strahls befindlichen Zellen in tangentialer Richtung, senkrecht zu den Längswänden. Dagegen sind die Querwände der von der Mediane seitlich gelegenen Zellen zu ihren Längswänden schief gerichtet, so dass sie mit den letzteren spitze, nach der Peripherie des Stammes gerichtete Winkel von $15-60^{\circ}$ bilden. Auffallend spitz sind diese Winkel bei Quercus oblongifolia ${ }^{4}$, laurifolia und glauca, wovon man sich bei Betrachtung von Querschnitten überzeugen kann. Nach der Maceration tritt die prosenchymatische Gestalt dieser im Mittel $0,14 \mathrm{~mm}$ langen und $0,020 \mathrm{~mm}$ breiten Markstrahlzellen am deutlichsten hervor. Sehr eigenthümlich ist auch das Vorkommen ungewöhnlich hoher platter Zellen, die vertical $0,10 \mathrm{~mm}$ messen und neben relativ niedrigen $0,02 \mathrm{~mm}$ hohen Zellen stehen. So in den breiten Markstrahlen von Quercus oblungifolia $\left.{ }^{5}\right)$. Die Grössenverhältnisse der Markstrahlzellen werden durch folgende Zahlen am besten verdeutlicht werden.

\section{Länge $\quad 0,05 \mathrm{~mm}$ im Mittel $^{8}$ )}

Höhe und Breite 0,022 - - -

Die Wände der Markstrahlzellen fand ich $0,0041 \mathrm{~mm}$ dick. Gewöhnlich besitzen sie cinfache $0,003-4 \mathrm{~mm}$ weite Poren. Doch

1) oder stark von Holzzellen durchsetzt.

2) Seltener sind sie horizontal 3 Zellen breit.

3) Fig. $3 \mathrm{~m}$.

4) Fig. $4 a$.

5) Fig. $4 b$.

6) Ias Jittel resultirt aus 171 Messungen aller untersuchten Eichenarten. 
zeigen sie an den Gefässen auch gehöfte Poren, deren Durchmesser $0,0087 \mathrm{~mm}$ und darüber ist.

Am dichtesten sind die in tangentialer Richtung stehenden kürzeren Wände der Markstrahlzellen geport, ein L'mstand, der die Böttcher nöthigt, die Fassdauben in radialer Richtung oder etwas schief zum Verlauf der Markstrahlen aus dem Eichenstamm herauszuschneiden. Sind auch die tangentialen Längswände der Markstrahlzellen dicht geport, wie bei Quercus Cerris ${ }^{1}$ ), Q. serrata und den amerikanischen "Black-Oaks", so eignet sich das Holz zur Anfertigung von Flüssigkeitsbehältern überhaupt nicht. Das Holz dieser Eichen gewährt hauptsächlich aus dem erwähnten Grunde dem Wasser leichter Zutritt, erweicht und wird leicht faul. Dagegen kann es sehr wohl zu Trockengefässen verarbeitet werden.

Die Markstrahlzellen, aber nur die der breiten Strahlen, zeigen Poren, die auf Zellzwischenräume ausgehen ${ }^{2}$ ), eine von Professor Caspary an Quercus pedunculata zuerst beobachtete Eigenthümlichkeit dieser Zellen. Ich fand sie in den breiten Markstrahlen vieler Eichen. Die Narkstrahlzellen führen nicht selten Stärkekörner, deren Grösse in den meisten Fällen $0,0087 \mathrm{~mm}$ war. Doch enthalten dic grossen breiten Narkstrahlen nur in gewissen Zellen und ganz ausschliesslich Stärke, die durch Jod leicht nachweisbar war. Andere, und zwar die meisten Markstrahlzellen hatten Gerbstoff zum Inhalt. Am besten war derselbe an der blauen Eisenreaction und ganz besonders auch bei Zusatz einer Lösung von bichromsaurem Kali zu erkennen. Die kleinen Markstrahlen führen meistens nur Gerbstoff. In den breiten Markstralılen vieler Eichen ${ }^{3}$ ) konnte ich die bereits erwähnten Krystalle von oxalsaurem Kalk wiederfinden. Ganz besonders zahlreich waren sie in den breiten Markstrahlen von Quercus

1) Wiesner: l. c. p. $60 t$ und uach werthvollen Angaben über amerikanische Eichenhölzer von Dr. Engelmann in einem Briefe an Herru Prof. Caspary vom 29. 8. 82 ans Brookline Mass.

2) Fig. 2 .

3) Quercus thalassica, Burgeri, paucilammellosa, dilatata, lanuginosa, Ilex, llex var. Fordii, coccifera, Calliprinos, rugosa, agrifolia, Suber, Turneri, oblongifolia, coccinea, serrata, Phellos, palustris, rubra, rubra var. texana, tinctoria, Kelloggii, austriaca, Cerris, laurifolia, falcata, stellata, Garryana, undalata var. grisea, iberica, castaneifolia, hicolor, Michauxii, heterophylla, alba, lyrata, Wislizeni, macrocarpa. 
laurifolia, Michauxii und Wislizeni zu beobachten. Neben den erwähnten Bestandtheilen des Zellinhalts der Markstrahlen kommt auch Harz in kleinen Quantitäten vor, dureh essigsaures Kupfer (Unverdorben-Franchimont'sches Reagens) und Hanstein's Anilinviolett nachweisbar.

Die Hauptbestandtheile des Eichenstammes sind: die Markstrahlen, das primäre und das secundäre Holz. Ersteres ist in einer dünnen Schicht um den centralen Markiörper gelagert, wurde ron Hill1) zuerst genaner erkannt und beschrieben. Li nennt es corona medullaris (circle of propagation) weil er annalım, dass es zum Wachsthum des Stammes wesentlich beitrage: eine irrige Behauptung, die durch besserc Beobachtung beseitigt wurde.

Dieses primäre Holz, auch Markscheide genannt, wird von den erstgebildeten Bestandtheilen des Stammes zusammengesetzt und enthält Schraubengefïsse und sehr enge Schraubenleitzellen in mehr oder weniger radialer Anordnung. Die Gefässe sind hier fast durchweg leiterförmig durchbrochen, während die Durchbrechung mit rundem Loch seltener zu beobachten ist. Dagegen sind im secundären Holz aller von mir untersuchten Eichen mit Ausuahme von Q. cuspidata²) und Q. pedunculata im Splint, wo an einigen Gefässen auch cine leiterförmige Durchbrechung zu bemerken war, die Gefässe mit rundem oder langelliptischem Loche durchbrochen. Die Porenleitzellen mit ihren dünnen Wänden und meist quergestellten Poren sind nur in der Markscheide zu finden, aber keineswegs im secundären Holz. Ich hebe dieses ausdrücklich hervor, weil Wiesner die dünnwandigen, gefässähnlichen Uebergangszellen $\left.{ }^{3}\right)(-$ Tracheiden C. Sanio z. Theil), die im secundären Holz nur in der Nähe ron Gefässen stehen, für "getüpfelte Leitzellen" ${ }^{4}$ ) hült. Nach Prof. Caspary ${ }^{5}$ ) kommen Leitzellen nur in der Markscheide vor. Zwar sind die Be-

1) l. e. p. 24 .

2) Fig. 11 .

3) Auf den Rath des Professors Caspary nenne ich diese weiten, oft schon an einem Ende durchlöcherten Zellformen „Uebergangszellen“, weil sie tn der That einen Uebergang der dünnwandigen Holzspitzzelle in das Gefäss vorstellen und in morphologischer Hinsicht zwischen beiden die Mitte halten.

4) Wiesner: 1. e. p. 605.

5) Pringsh. Jahrb. Bd. IV. p. 101. 
standtheile der letzteren von denen des secundären Holzes genetiseh und morphologisch-verschieden, schon an der Art ihrer Verdickung leicht kenntlich, doch zeigen sie bei vielen Eichen in demselben Theil des Stammes gleiche Gestalt und Anordnung, eignen sich daher mehr zur Charakterisirung der Gattung als der Art und werden von mir nicht weiter berïcksichtigt werden. In sehr vielen Fällen konnte ich nur über das bereits ansgewachsene seeundäre Holz verfügen, zu dessen Bestandtheilen ich mich jetzt wende.

Zwischen der Markscheide und der Rinde befindet sich der mächtige Cylinder des secundïren Holzes radial von den verschiedenen bereits erwähnten Markstrahlen durchzogen und zum grössten Theil von dickwandigen Holzspitzzellen zusammengesetzt. Eine Ausnahme hiervon macht nur die nordamerikanische Quereus lyrata Walt., in deren Holz die weitlichtigen Gefässe, Uebergangs- und Stumpfzellen ïber die Holzspitzzellen offenbar das Uebergewicht haben.

Bei unseren nordischen Eichen und vielen anderen Arten mit periodisch wechselnder Belaubung bemerken wir auf Stammquerschnitten eine dentliche Sonderung der Bestandtheile des Holzes zu concentrischen Lagen, den sogenannten Jahresringen, da sie den jährlichen Zuwachs des Holzes bezeichnen. Alle Jahresringe eines völlig ausgewachsenen Stammes zeigen einen nahezu gleichen Bau, da sie gleiche Zellarten in bestïndiger Aufeinanderfolge enthalten und nur die Quantität der letzteren, nicht etwa eine morphologische Verschiedenheit, bedingt eine Abänderung in räumlicher Hinsicht. Eine abweichende Anordnung der Zellen des secundären Holzes ist nur in jungen Stïmmen zu bemerken. So sind z. B. bei Quereus pedunculata und vielen anderen Eichen in den ersten Jahresringen die grossen weiten Gefässe blos radial angeordnet, und ihre Wünde sind dünner. In später gebildeten Jahresringen sind sie im Frühlingsholz tangential mahestehend anzutreffen, so dass ihre Anordnung concentrische Kreise erkennen lïsst, wodurch ein Jahresring dentlich begrenzt wird. Aber nicht alle Eichenarten besitzen den gleichen Stammbau.

Bei den meisten immergrünen Eichen sind die Jahresringe nicht dureh tangential nahestehende, weite Gefässe im Frühlingsholz begrenzt, kömnen mit blossem Auge nicht deutlich wahrgenommen werlen und selbst mit Hülfe des liikroskops sind sie bei Quercus 
dilatata, paucilammellosa nnd chrysolepsis oft nicht 7.0 finclen. Dieses kommt daher, dass bei den meisten immergrünen Eichen kein periodischer Stillstand in der Vegetation eintritt, wodurch eine wesentliche Abänderung der Zelldimensionen bewirkt wird. Durch die continuirliche Thätigkeit des Cambiums werden in stetiger Aufeinanderfolge die gleichen Bestandtheile ohne bedeutende $\mathrm{Abweichung}$ gebildet. Nur bei den immergrünen Eichen: Quercus Wislizeni, castaneifolia, glandulifera, serrata und zum Theil auch bei Qu. cuspidata $^{1}$ ) wie bei $Q$. agrifolia sind die Grenzen der Jahresringe durch weitere Gefässe im Frühlingsholz markirt und daher schon mit blossem Auge sichtbar. Mit dem Mikroskop erkennt man jedoch in sehr vielen Fällen sogar die Grenzen der scheinbar undeutlichen Jahresringe. Bei den meisten immergrünen Eichen, in deren Stämmen gleich grosse isolirte Gefässe in radialen Zïgen angeordnet stehen, kann man dennoch kürzere oder längere, tangentiale schmale Reihen dunklerer Holzzellen ${ }^{2}$ ) entlecken, durch welche die Jahresringe angedeutet werden. Bei den japanesischen immergrünen Eichen, die ich untersuchen konnte, werden sie durch diese dickwandigen concentrisch gelagerten tangential breiten Holzzellen recht regelmässig bezeichnet. Die darauf folgenden Zellen des nächsten Jahresringes sind etwas weitlichtiger, doch besitzen die Gefässe bei einem Durchmesser von $0,17 \mathrm{~mm}$ gleiche Weite, sind völlig isolirt und nach dem Typus der immergrünen Eichen radial angeordnet. Diese Verhältnisse zeigen Querschnitte von Quercus glabra, glauca, gilva, thalassica, Burgeri und cuspidata sehr deutlich. Weniger gut ausgeprägt sind die Jahresringe bei folgenden immergrünen Arten: Quercus virens, oblongifolia, Ilex nebst der var. Fordii, Suber, coccifera, lanuginosa, Calliprinos und rugosa.

1) Auch bei Castanopsis chrysophylla.

2) Th. IIartig nennt diese Zellen "Breitfasern" (Leben der Pflanzenzelle p. 42). Ueber die Unzulässigkeit dieser Bezeichnung vrgl. C. Sanio in der Bot. Zeitung von 1863 , No 11. 


\section{G e f äs s e.}

In den Stämmen der Eichen mit abfallendem Laube, wie auch einiger immergrüner Arten, bemerkt man auf Querschnitten zwei Arten von Gefässen, die sich durch Weite und Anordnung von vornherein unterscheiden. Während die grossen $0,30-0,45 \mathrm{~mm}$ weiten Gefässe sich im Frühlingsholz befinden ${ }^{1}$ ), wo sie dicht stehend concentrische Kreise zusammensetzen, sind andere, $0,02-0,20 \mathrm{~mm}$ weite, sogenannte kleine Gefässe ${ }^{2}$ ) in schmäleren und breiteren Zügen radial quer durch den Jahresring angeordnet, so dass sie auf dem Querschnitt im Ganzen ein baumartiges Bild oder hellere Streifen von verschiedener Breite erkennen lassen. Doch konnte ich in schmäleren Jahresringen letztere anch in einer zum Radius schief gehenden Richtung angeordnet vorfinden. Stets sind die Gefässe von weitlichtigen Uebergangs- und Stumpfzellen umgeben. Seltener finden sich dickwandige Holzspitzzellen in ihrer Nähe. Wie bereits erwähnt, sind in den Stämmen der meisten immergrünen Eichen nur Gefässe einerlei $\mathrm{Art}^{3}$ ) anzutreffen, deren Weite $0,15 \mathrm{~mm}$ im Mittel beträgt, mithin in Bezug auf die weiten Gefässe der Eichenarten des anderen Typus gering zu nennen ist. Diese gleichweiten Gefässe lassen nur eine radiale Anordnung erkennen und ihre Wände sind im Wittel $0,0087 \mathrm{~mm}$ dick, eine Eigenthümlichkeit, die sie allerdings mit den kleinen Gefässen einiger Arten der Eichen mit wechselnder Belaubung gemein haben. - Am kürzesten sind die weiten Gefässe des Frühlingsholzes bei Quercus pedunculata ind mongolica, wo der Querdurchmesser die Lünge des Gefässes ïbertreffen kann. Bei ersterer war ein Gefüss $0,20 \mathrm{~mm}$ lang und $0,32 \mathrm{~mm}$ weit, bei letzterer ein solches von $0,26 \mathrm{~mm}$ länge und $0,35 \mathrm{~mm}$ Weite anzutreffen. Beide zeigten das Aussehen kurzer gerader Cylinder; aber nicht immer ist die Gestalt der Gefässe so regelmässig. Ihre Enden sind in den meisten Fällen schnabelartig ausgezogen ${ }^{4}$ ). In dem Holz von Quercus Wislizeni, thalassica und cuspidata sah ich Gefässe mit $0,17 \mathrm{~mm}$ langen Schnäbeln. Dieselben stiessen mit schiefen

1) Fig. $27 \mathrm{G}$ น. $28 \mathrm{G}$.

2) Fig. $27 \mathrm{~g}$ u. $28 \mathrm{~g}$.

3) Fig. 29 G.

4) Fig. 6,7 u. 9 . 
Enden aufeinander und communicirten durch rundliche oder elliptische Löcher. Das Ende eines Getässes kann auch durch zwei einander genäherte Löcher mit zwei anstossenden Gefässen in Verbindung stehen, wie ich an macerirtem Naterial von Quercus pedunculata $^{1}$ ) und oblongifolia ${ }^{2}$ ) beobachten und abbilden konnte.

Nicht immer findet sich die Durchbrechung des Gefässes an dessen Ende; bei Quercus oblongifolia kommt sie nahezu in der Mitte der engeren Gefässe vor. Bei den Gefässen des secundären Eichenholzes ist die Durchbrechung mit grossem länglich rundlichem Loche Regel, doch kommt an den Gefässen von Quercus pedunculata hin und wieder die leiterförmige Perforation vor, namentlich im Splint. Dasselbe konnte ich im Holze von Quercus cuspidata beobachten, wo diese Art der Durchbrechung der Gefässe öfter vorkommt, wie ich bereits erwähnt habe.

Die Gefässe köunen einfach und gehöft geport scin. Sobald sie an Markstrahlen stossen, werden ihre Wände unregelmässig weit, zuweilen gehöft geport. Dic Poren sind flach, im Umriss elliptisch oder länglich, fast viereckig. Eine völlige Resorption der Gefüsswand konnte ich hier nicht feststellen. Gefïsse mit solchen breiten Poren werden von Professor Caspary ${ }^{3}$ ) als gefelderte" bezeichnet. ${ }^{4}$ ) Diese flachen grossen Poren sind an den grossen Gefïssen von Quercus pedunculata sehr unregelmässig gestellt und zuweilen doppelt begrenzt. Bei den immergrïnen Eichen ${ }^{5}$ ), besonders aber an den Gefässen von Quercus glabra, rugosa, chrysolepis sah ich sie nicht selten sehr regelmässig lïnglich viereckig. Die Markstrahlzellen zeigten in diesem Falle regelmässige, quer iiber die Breite dor Wand sich erstreckende Poren. Ganz dieselbe Erscheinung konnte ich an Holzstumpfzellen ${ }^{6}$ ) wahrnehmen, wenn dicselben am Gefäss standen. Letzteres besass dann leiterförmig angeordnete Poren, was recht häufig im Splint der immergrünen Arten wahızunehmen war, doch

1) Fig. 5.

2) Fig. 6 .

3) „Ueber die Gefässbündel der Pflanzen". Monatsberichte der Fiönigl. Akademie der Wissenschaften zu Berlin, 10. Juli 1862.

4) Fig. 8 .

5) Fig. 9.

(6) Fig. 25 . 
kommen sie auch im Kernholz daselbst vor. Ausser diesen Poren liessen sich auch recht deutlich gehöfte erkennen, welche vom Gefäss auf die Markstrahlzellen ausgingen. So bei Quercus pedunculata und Q. Iyrata. Auch gegen Stumpfzellen sind sie gehöft geport neben der bereits erwähnten Modification. Von allen Porenarten sind an Gefässen die gehöften die verbreitetsten. Nicht selten kommen sie spaltenförmig vor, wobei der Hof kleiner als der Spalt ist. - Der Durchmesser der Hofpore betrïgt 0,0087-0,01 mm. Der Porengang ist in den meisten Fällen 0,003-0,004 $\mathrm{mm}$ weit. Niemals habe ich bei Eichen die Hofporen sechsseitig begrenzt vorfinden können, selbst da nicht, wo sie z. B. bei Quercus paucilammellosa, dilatata und oblongifolia am Gefïss sehr dicht stehen, während es bei Ulmus doch recht lüufig vorkommt, dass dichtstehende Hofporen sechsseitige Umrisse zeigen. Bei Quercus cuspidata waren sie an Gefüssen weniger dicht, aber desto grösser und regelmïssiger angeordnet zu beobachten. Die Gefässe unter einander und auch mit den Uebergangszellen stehen seitlich nur durch Hofporen in Verbindung.

In den Gefïssen der meisten Eichen konnte ich Thyllen ${ }^{1}$ ), Stopf- oder Füllzellen vorfinden. Sie stellen höchst unregelmässig begrenzte, meist dünnwandige, gelbe oder braune Zellen vor, die den angrenzenden Stumpfzellen entstammen dürften. In den Gefässen der Quercus chrysolepis konnte ich deutlich wahrnehmen, dass sie sich durch die Poren aus anliegenden Stumpfzellen hereindrängten. Ihre Wände sind einfach geport, doch kann der Porengang nur $0,0041 \mathrm{~mm}$ weit sein, wie bei Quercus stellata²), aber er kann auch etwas weiter und die Pore bei elliptischer Umgrenzung sehr flach sein, wie z. B. bei Thyllen der Gefässe von Quercus pedunculata und vieler anderer Eichen. Fast sklerenchymatisch bei kugelrunder Gestalt fand ich sie in den Gefüssen von Quercus castaneifolia und aquatica. Sie enthalten zuweilen Gerbstoff, und bei Quercus Kelloggii ${ }^{3}$ ) konnte ich in diesen Zellen auch Stärkekörner vorfinden. Gewöhnlich sind sie in den Gefässen sehr locker

1) Botanische Zeitung, Jahrg. 1845, p. 225; 1868.

2) Auf Fig. 12 sind sie coniseh und ersehtinen auch gehöft.

3) Fig. 13. 
und wenig gedrängt anzutreffen, doch füllen sie das Lumen derselben bei Quercus paucilammellosa und dilatata vollkommen, zu dichten Zellmassen geballt.

\section{Uebergangszellen.}

In der Nähe der Gefässe und nur hier befinden sich die Uebergangszellen ${ }^{1}$ ). Sie sind eine gefässartige Modification der Holzspitzzellen, unterscheiden sich jedoch von diesen durch ihre dünnen Wände $(0,0041 \mathrm{~mm})$, die stets mehr oder weniger spaltenförmige gehöfte Poren in linksläufiger Spirale angeordnet aufweisen. Ihre Wände zeigten in keinem Eichenholz irgendwelche Verdickung von Ring- oder Spiralform.

Auch in der Länge sind sie von den kleinen engen Gefässen äusserst wenig verschieden. Sie sind bei allen untersuchten Eichenarten im Nittel $0,50 \mathrm{~mm}$ lang und $0,017 \mathrm{~mm}$ weit. Am längsten fand ich sic bei Quercus alba (1,18 mm lang), am kürzesten bei Q. Durandii und Q. lyrata (nur $0,20 \mathrm{~mm}$ lang). Ihre Enden sind nicht selten doppelt gekniet, wenn sie an Markstrahlen vorübergehen. Doch siud ihre Spitzen auch in Form von Widerhaken, wie bei Quercus Wislizeni und Q. virens hin und wieder za beobachten. Gar nicht selten sind ihre Enden fussförmig ${ }^{2}$ ) erweitert oder gabelig getheilt $\left.^{3}\right)(Q$. Wislizeni u. a.). Die Gefüsse drücken sie meist etwas flach, wobei ihre Wände verbreitert und wegen der Poren nach dem Zellinnern zu gezackt erscheinen. In den meisten Fällen führen sie keinen Inhalt (nur bei Quercus dilatata und paucilammellosa enthalten sie Gerbstofi).

1) Tracheiden, C. Sanio, Botanische Zeitung 1860, p. 201.

2) Fig. $16 \mathrm{a}$.

3) Fig. 17. 


\section{Holzspitzzellen.}

Ben vorigen Zellen sind die dickwandigen Holzspitzzellen am ïhnlichsten. Im wezentlichen kann man bei allen Eichen zwei Modificationen dieser Zellen unterscheiden:

1. die ungetheilte Spitzzelle, welche sowohl ohne als auch mit beiden Porenarten vorkommt;

2. die getheilte oder gefächerte Holzspitzzelle (= prosenchyma septatum C. Sanio).

Letztere ist in der Grundmasse des Eichenholzes nur sehr spärlich vertreten. Am zahlreichsten konnte ich sie bei Quercus Garryana vorfinden. Die enge dickwandige ungetheilte Holzspitzzelle bildet bei den meisten Eichenstämmen die Grundmasse des secundären Holzes, nur bei Quercus lyrata haben die weitlichtigen Zellen über sie ein merliliches Uebergewicht in quantitativer Hinsicht. Die Holzspitzzellen sind hier in radial gestellten Gruppen anzutreffen, die von Ginander durch radiale Gefäss- und Uebergangs- wie auch Stumpfzellgruppen, die Markstrahlen nicht zu vergessen, getrennt werden. Diesem Umstande schreibe ich die Leichtigkeit und Weichheit des Holzes ron Quercus lyrata zu. Die dickwandigen Holzspitzzellen tragen wesentlich zur Schwere des Holzes bei. Es war schon Du Hamel du Monceau') bekannt, dass das Kernholz mit dickwandigen Spitzzellen schwerer und dichter ist als der Splint mit rorwiegend weitlichtigen Zellarten. In den Stämmen der immergrünen Arten Quercus dilatata, chrysolepis, paucilammellosa, glabra, glanca, gilva, Burgeri, virens, lanuginosa, rugosa und virens sind sie die vorherrschende Zellart.

Die Länge der Holzspitzzellen fand ich bei allen untersuchten Eichen im Mittel (aus 171 Messungen) 1,224 mm, die Breite 0,017. Die külzesten Holzspitzzellen beobachtete ich an einem allerdings jungen Stamme von Quercus Calliprinos. Sie massen nur 0,308 mm. Die längsten fand ich im ausgewachsenen secundären Holz von Quercus aquatica mit einer Lünge von $2,04 \mathrm{~mm}$ und der im Mittel angegebenen Breite: sie sind mithin die lïngsten Holzspitzzellen,

1) Dn IIamel c! IIonceau: „De l'exploitation des bois", p. 122 u. 476. 
denn (. Saniol) fand nach seinen umfangreichen Untersuchungen die bedeutendste Länge dieser Zellen bei Avicennia sp., in deren Holz sie $2 \mathrm{~mm}$ messen sollen. - Am weitlichtigsten fand ich die Holzspitzzellen bei den weniger dauerhaften Stämmen der Arten Quercus Garryana, Phellos, Prinos, nigra, Catesbaei und agrifolia, wo sie $0,02-0,03 \mathrm{~mm}$ breit sind.

Das Holz dieser Eichen lïsst sich auch leichter schmeiden, als das der anderen Arten. Die schmalsten und englichtigsten Holzspitzzellen besitzen Quercus heterophylla, grisea, dilatata und chrysolepis. Sie sind hier bei oft verschwindend kleinem Lumen nur 0,013 $\mathrm{mm}$ breit. Die Zellwände bestehen nur aus zwei Schichten:

1. aus der dünnen äusseren Zcllwand und

2. aus der bedeutend dickeren inneren der ersten von innen aufgelagerten Schicht, die nach Ablösung der äusseren Zellwand bei Quercus oblongifolia eine spiralige Faltung erkennen liess.

Doch habe ich auch hier diese Erscheinung nicht oft beobachten können. Eine dritte anfgelagerte gallertartige Misse, welche C. Sanio für dickwandige Spitzzellen einiger Hölzer angiebt, konnte ich bei den Eichen nach Anwendung von Chlorzinkjod nicht wahrnehmen. In dem Holz aller von mir untersuchten Stämme kommen die Holzspitzzellen sowohl ganz ungeport als auch geport vor, doch gehören die meisten Poren derselben zur Kategorie der Hofporen mit schräg zur Längsachse der Zellen gerichtetem schalem Spalt, welcher länger als der Durchmesser des Hofes ist. Einfache Poren kamen an diesen Zellen nur hin und wieder vor. In mittleren Theile des Jahresringes, wo die Holzspitzzellen dichte Massen zusammensetzen, sind sie ungeport. Gehöfte Poren zeigen die glatten Zellen am Schlusse jedes Jahresringes, wo sie radial 2-5 Iagen mächtig die Grenzen des Herbstholzes bezeichnen. Sie sind hier tangential verbreitert, wurden deshalb von Th. Hartig ${ }^{2}$ ) "Breitfasern" genannt, besitzen 2-4 Reihen radial gerichtoter Hofporen, von denen 1 resp. 2 anf den dem Frühlingsholz zugekchrten und die anderen, diesen entsprechend, auf den dem Herbstholz zugewandten Seitenflächen sich

1) Botanische Zeitung 1863 .

2) Th. Hartig: „Leben der Pflanzenzelle“ p. 4\%. 
befinden. Gileich hinter diesen sieht man andere diekwandige Spitzzellen im Herbstholz, die auf dem Querschnitt mehr oder weniger rundlich erscheinen und deren Poren nach allen Richtungen der Windrose angeordnet sein können. Die Hofpore hat im Durchmesser $0,0087 \mathrm{~mm}$, wovon in den meisten Fïllen 0,0032-0,004 min auf den Porengang kommen. Die grössten Iofporen sah ich an den Iolzspitzzellen von Qnereus cuspidata, dilatata, Castanopsis indica und C. chrysophylla, wo sie nicht selten die ganze Breite der Zellwand $(0,0020 \mathrm{~mm})$ einnehmen. Die Enden der Holzspitzzellen sind bei Eichen nicht nur zwei-, sondern auch dreispitzig ${ }^{1}$ ) anzutreffen. Nicht selten kommen seitliche Aussackungen der Zellwand vor, und hin und wieder waren auch Holzspitzzellen mit einem völlig stumpfen Ende anzutreffen ${ }^{2}$ ). In den breiten Markstrahlen von Quereus glabra, virens, oblongifolia, paucilammellosa und anderen Fichenhölzern finden sich zuweilen verbreiterte Spitzzellen, die vielleicht die Auffassung zulassen, sie für verholzte Mutterzellen der Markstrahlen zu halten. Sie gewähren nicht selten den Anschein, als ob Spitzzellen sich zu Markstrahlzelien unwandelten, was ja im abgestorbenen Holz durchaus nicht stattfinden kann. Kommen Holzspitzzellen in der Näho breiter Markstrahlen vor, die verhältnissmässig niedrig sind, wie in den Stämmen von Quercus Cerris ${ }^{3}$ ), serrata, oblongifolia, rugosa, so werden besonders die zwischen zwei vertical ïbereinanderstehenden Narkstrahlen befindlichen bedeutend gekrümmt. Berïhren die Enden der Holzspitzzellen Markstrahlzellen, so werden sie eigenthümlich flachbuchtig gezähnt ${ }^{+}$). Dadurch, dass diese Zellen mit ihren Enden zwischen einandergreifen und ein lebhaftes Spitzenwachsthum entwickeln, schieben sie sich nicht selten umeinander. Ich konnte besonders deutlich bei Holzspitzzellen von Quercus oblongifolia ${ }^{5}$ ) in einander verflochtene Enden vorfinden. Dieser Umstand trägt viel zur Zähigkeit des Holzes bei, doch soll nach Sargen $t^{6}$ ) gerade das

1) Fig. 19 .

2) Fig. 21 a.

3) desgl.

4) Fig. $18 a$.

5) Fig. 26.

6) Sargent: "A catalogue of the forest trees of North-America" p. 50. 
Holz der letzterwähuten Art brüchig sein, was durch die chemische Beschaffenheit der Zellwände begründet sein dürfte.

Die Eichenholzspitzzellen sind in den meisten Fällen leer, doch konnte ich in einigen derselben, bei Quercus paucilammellosa und dilatata, Gerbstoff entrlecken, eine Eigenthümlichkeit, die bis jetzt C. Saniol) nur bei Syringa vulgaris beobachtet hat.

\section{Holzstumpfzellen.}

$\mathrm{Zu}$ den dünnwandigsten, weitlichtigen Bestandtheilen des Eichenholzes gehören die Stumpfzellen. Sie kommen bei allen Eichen in menr oder minder deutlichen, längeren oder kürzeren, tangentialen unterbrochenen Binden vor ${ }^{2}$ ). Besonders unter den dichtstehenden Holzepitzzellen des Herbstholzes ist ihre tangentiale Auordnung schon mit blossem Auge bemerkbar; sind ihre Reihen jerloch vielfach von Spitzzellen unterbrochen, so sind sie nicht mehr deutlich zu erkennen. Sie erscheinen dann, unter dem Mikroskop betrachtet, im Querschnitt in maschiger Anordnung ${ }^{3}$ ). Im Frühjahrsholz kann man sie mit blossem Auge überhaupt nicht wahrnehmen. Hier sind alle Zellen mehr oder minder weitlichtig, ausserdem stehen die Holzstumpfzellen daselbst zerstreut. Mit dem Mikroskop erkennt man sie auf dem Querschnitt an den reichlich geporten Querwänden. Ich fand ihre Länge im Nittel $0,09 \mathrm{~mm}$, die Breite $0,02 \mathrm{~mm}$. Selten waren sie über $0,1 \mathrm{~mm}$ lang: So bei Quercus mongolica, Garryana, tinctoria, pancilammellosa, lanuginosa, Burgeri und cuspidata. Teher $0,03 \mathrm{~mm}$ breite Holzstumpfzellen waren bei Quercus dilatata, paucilammellosa und Burgeri zu finden.

Am regelmässigsten ausgebildet, ohne Abweichung ron der typischen Form sind sie im Herbstholz anzutreffen. Dagegen erfährt ihre Gestalt im Frühlingsholz unter dem Druck der weiten Gefässe

1) Botanische Zeitung 1863 .

2) Fig. 27 st u. $28 \mathrm{st}$.

3) Fig. 28, 29, 30. 
eine wesentliche Abänderung, indem sie ron letzteren theils breitgedriickt, theils auseinandergezerrt werden. Sie zeigen in diesem Falle längere Fortsätze, welche mit ähnlichen Fortsätzen benachbarter Stumpfzellen zusammenstossen ${ }^{1}$ ) oder auch frei endigen ${ }^{2}$ ). In ersterer Form communiciren die Fortsätze durch eine Pore, in letzterer nicht. Zuweilen communiciren zwei benachbarte Stumpfzellen durch einfache Poren, die an seitlichen Ausbauchungen stehen, wie ich es besonders gut ausgeprägt bei Quereus Kelloggii ${ }^{3}$ ) vorfand. Von oben betrachtet erscheinen dann die Stumpfzellen mit Porengruppen auf den Längswänden. C. Sanio beobachtete die ersterwähnte Eigenthümlichkeit an den Stumpfzellen der Porliera hygrometrica ${ }^{4}$ ) zuerst und citirt in der Botanischen Zeitung von 1863 noch einige Hölzer, deren Stumpfzellen Aehnliches im Bau zeigen. Diese ron ihm als „,conjugirtes Parenchym" bezeichneten Zellen sind bis jetzt noch in keiner Eiche beobachtet worden, um so merkwürdiger, da sie gerade in dem secundären Holz der so oft bearbeiteten Quercus pedunculata und Cerris nicht selten sind und gut ausgeprägt vorkommen.

Ich habe es vorfinden können bei Quercus Durandii, alba, iberica, grosseserrata, mongolica, macranthera, palustris, sonomensis ${ }^{5}$ ), imbricaria, aquatica, heterophylla, Catesbaei, coccinea, falcata, laurifolia, nigra, Phellos, rubra, rubra var. texana, tinctoria, Prinus, bicolor nebst var. Michauxii, Garryana, lobata, lyrata, stellata, macrocarpa, Suber, dilatata, glandulifera, castaneifolia, serrata, lanuginosa, coccifera, virens, oblongifolia, chrysolepis, agrifolia, hypoleuca, Wislizeni, paucilammellosa and cuspidata. Q. pedunculata und Cerris habe ich bereits vorhin genannt. Die Poren der Holzstumpfzellen sind meist einfach, doch können sie gegen das Gefäss auch gehöft und elliptisch sein, wie ich besonders an immergrünen Eichenhölzern zu beobachten Gelegenheit hatto und bereits bei Beschreibung der Gefässe erwähnte.

Sie führten in den meisten Fällen Stärke, aber auch Gerbstoff war in ihnen nachzuweisen, namentlich bei Quercus dilatata und
1) Fig. 24.
2) Fig. 24 b u. 23.
3) Fig. 22 a.
4) Botanische Zeitung 1860, p. 197.
5) $=$ Kelloggii Nowb. 
paucilammellosa. Ich fand in den Stumpfzellen Stärke bei Quercus pedunculata, grosseserrata, Turneri, Cerris, sonomensis, imbricaria, heterophylla, laurifolia, Phellos, rubra, rubra var. texana, Michauxii, Ilex, Hlex var. Fordii, Suber, dilatata, glandulifera, castaneifolia, serrata, lanuginosa, Calliprinos, coccifera, virens, oblongifolia, chrysolepis, hypolenca, rugosa, glabra, thalussica, paucilammellosa. Iu den Stumpfzellen folgender Arten liessen sich besonders in vier Nähe grosser Markstrahlen Krystalle ron oxalsaurem Kalk beobachten: Quercus macrocarpa, lyrata, alba, Durandii, Wislizeni (selır zahlreich), heterophylla, glandulifera, bicolo:, Michanxii, castaneifolia, iberica, grisea, Garryana, stellata, nigra, falcata, laurifolia, Cerris, austriaca, sonomensis, tinctoria, rubra, rubra var. texana, palustris (selten), Phellos, serrata, coccinea, lyypoleuca, virens, oblongifolia, Turneri, Suber, agrifolia, rugosa, Calliprinos, coccifera, Ilex, Ilex var. Fordii, lanuginosa (zahlreich), dilatata (selten), paucilammellosa, Burgeri und thalassica.

Nachdem ich im Vorhergehenden die anatomischen Verhältnisse des inneren Baues des Eichenholzes genauer erörtert habe, werde ich nunmehr zur Gruppirung der Artell nach anatomischen Merkmalen iibergehen. Im Allgemeinen sind Zellen und Gefässe im Eichenholz in Hinsicht der Gestalt nicht so sehr verschieden und werden daher von mir im Folgenden anch nur in Bezug auf ihre Anordnung in den einzelnen Jahresringen berücksichtigt werden. Es liessen sich hauptsächlich nach den Lagerungsverhältnissen der Gefässe und Stumpfzellen gewisse Gruppen bilden, welche die Merkmale der Arten im Allgemeinen zusammenfassen, so dass im Holz der einzelnen Art nur kleinere Abweichungen vom Charakter der Gruppen zu finden sind.

Die charakteristischen Merkmale der Eichenhölzer lassen sich makroskopisch bei Anwendung einer etwa viermal vergrössernden Loupe, sowie von doppeltchromsaurem Kali leicht finden. Zunächst glättete ich mit einem scharfen Messer den Querschnitt, wodurch die Lagerungsverhältnisse der verschiedenen zelligen Bestandtheile im Holzstamm deutlich hervortraten. Das Mikroskop diente mir nur zur genaueren Beobachtung der Breiten- und Stellungseigenthümlichkeiten einzelner Holzbestandtheile.

Auf dem tangentialen Schnitt konnte ich die horizontale und 
verticale Ausdehnung sowie auch die Anordnung der breiten Markstrahlen beobachten, deren Durchschnitt besonders nach Bepinselung mit doppeltchromsaurem Kali von den umgebenden Holzzellen deutlich wurde. Die Angaben über die Zahl der breiten Markstrahlen für eine Fläche von 15 qmin beziehen sich lediglich auf die Tangentialschnitte in der Nähe der Peripherie des Stammes. Die kleinen schmalen Markstrahlen berïcksichtigte ich nicht weiter, da sie bei nahezu gleicher Höhe und Breite nichts Charakteristisches darbieten.

Die radialen Schnitte weisen zwei wesentliche Nerkmale des Eichenholzes auf. Man beinerkt auf ihren Flächen:

1. die sogenannten ,Spiegel", welche durch Höhe und Breite grosser Markstrahlen bedingt werden und in einigen Eichenhölzern eine charakteristische Farbe besitzen.

Bei Quercus dilatata ${ }^{1}$ ) sind sie nicht dentlich wahrzumehmen und im Holz von Quercus cuspidata ist ihr Vorkommen sehr selten.

2. lassen sich mehr oder weniger deutliche parallele Längsstreifen in gleichmässigen Abständen erkennen, die von der Anordnung der Stumpfzellen zu mehr oder weniger deutlichen tangentialen Reihen herrühren.

Ich wurde auf dieses eigenthümliche Aussehen der Radialschnitte besonders durch die Untersuchung japanesischer Eichen aufmerksam und konnte es im Holze anderer Arten, wenn auch weniger deutlich, wiederfinden.

\section{Eintheilung der Eichenhölzer nach ihrem anato- mischen Bau.}

A. Mit breiten hohen Markstrahlen, die nebst kleinen schmalen Strahlen (1-2 Zellen ${ }^{2}$ ) breit, 8-30 Zellen hoch) im Holzstamm radial angeordnet sind. Die Stumpfzellen stehen entweder in con-
1) Fig. 29.
2) Sehr selten sind sie 3 Zellen breit. 
centrischen Kreisen oder in längeren und kürzeren tangentialen Reihen unter den dickwandigen Holzspitzzellen des Jahresringes. In jüngeren Stämmen zeigen sie eine grössere tangentiale und radiale Anuäherung. In den später gebildeten Jahresringen ist die tangentiale Anordnung vielfach dureh die Holzspitzzellen verwischt und gewährt auf dem Querschnitt mit dem Vikiroskop betrachtet ein maschiges Bild.

a) Jahresringe durch grosse $0,31 \mathrm{~mm}$ weite Gefässe, die zu (geschlossenen) concentrischen Kreisen im Frühlingsholz angeordnet sind, sowie durch breite gehöft geporte Holzspitzzellen des äussersten Herbstholzes scharf begrenzt und schon mit blossem Ange deutlich wahrnehmbar. Kleine, nur $0,05-0,1 \mathrm{~mm}$ weite Gefä́sse sind im Jahresring in radial angeordneten Reihen vorhanden.

I. Mit dünneu Gefässwänden von $0,004 \mathrm{~mm}$ Breite. Die kleinen engen Gefässe erscheinen auf dem Querschnitt im Herbstholz nicht völlig cylindrisch rund.

a) Die radialen Ziigo enger Gefässe erscheinen auf dem Querschnitt im Frühlingsholz schmal, verbreitern sich nach der Peripherie zu und kommen im Herbstholz des Jahresringes regelmässig zur Vereinigung. Die einzelnen kleinen Gefässe sind mit blossem Auge nicht sichtbar, aber sie stehen von weitlichtigen, dünnwandigen Uebergangs- und Stumpfzellen umgeben, und erscheinen daher im Verein mit denselben als helle radiale Streifen oder Züge, die von den bräunlichen dickwandigen Holzspitzzellen durch ihre Färbung abstechen. Letztere pflegen besonders an den breiten Markstrahlen in schmaler radialer Schicht durch den ganzen Jahresring angeordnet zu sein; ausserdem befinden sie sich in radialen Gruppen zwischen den radialen Zïgen kleiner und den tangentialen grosser Gefässe, also im mittleren Theile des Jahresringes. Die grossen Gefässe im Frühlingsholz in mehreren Lagen, allseitig genähert, setzen breite concentrische Kreise zusammen.

† Radiale Züge kleiner Gefässe im Herbstholz von Spitzzellen seh selten getrennt. 


\section{Quercus lyrata Walt. ${ }^{1}$ )}

Over-Cup oak, Swamp Post oak, Water-White oak. ${ }^{2}$ )

Die Stumpfzellen zeigen im Allgemeinen eine tangentiale Anordnung, doch sind ihre Reihen oft ron dickwandigen Spitzzellen durchsetzt und nicht selten zu kïrzeren und längeren tangentialen Gruppen abgetrennt, was besonders unter dem Mikroskop dentlich wird. Die breiten Markstrahlen stehen horizontal 1--2 mm ab. Auf dem Tangentialschnitt kommen auf 15 qmm ungefähr 6 breite Markstrahlen vor, deren Höhe (verticale Ausdehuung) 60-75 mm beträgt. Thre Breite übersteigt noch nicht $0,5 \mathrm{~mm}$. Auf dem Radialschnitt sind hellgelbrothe breite „Spiegel" zu bemerken. Der Splint ist hellröthlich, das Kernholz dagegen etwas dunkler, fast rothbraun gefärbt. Die grossen Gefässe sind seitlich ein wenig zusammengedrïckt, besitzen aher die unter a) angegebene Weite. Dasselbe gilt von den kleinen Gefässen.

Der technische Werth des Holzes ist nach Dr. Engelmann ${ }^{3}$ ) kein geringer, obgheich es sich leicht schneiden lässt. Da bei ihm die weitlichtigen Bestandtheile überwiegen, ist sein Gewicht nicht bedentend.

Michaux fil. ${ }^{4}$ ) hält diese Species für die werthvollste aller Sumpfeichen.

Vorkommen $^{5}$ ): In den Sümpfen Nord-Carolinas, in den Thälern des Ohio, Sïd-Florida, Arkansas (wo sie nach Sargent selten sein soll), Texas.

$\dagger \dagger$ Die radialen Züge kleiner Gefïsse sind breit und sind sowohl getrennt als anch vereint im Herbstholz anzutreffen. Ersteres findet namentlich im Kernholz, letzteres im Splint statt. Die Holzspitzzellen kommen in grösseren Gruppen zwischen den radialen Zïgen vor.

1) Sargent'sche Holzsammlung No. 226.

2) Die englischen Namen der einzelnen Eichenarten gebe ich nach Sargent, wie er sie in seinem ${ }_{n}$ Catalogue of the forest trees of North-America " gebraucbt hat.

3) Nach Mittheilungen in einem Briefe an Professor Caspary.

4) Histoire des chênes No. 3.

5) Cb. Sargent: "A catalogue of the forest trees of North-America" p. 49. (Die geographische Verbreitung der nordamerikanischen Eichen gebe ich nach den Angaben dieses Autors.) 
2. Quercus alba L. ${ }^{1}$ )

White oak. Syn.: Q. palustris Jarsh.

Q. pinnatifida Walt.

Die grossen (Gefässe ${ }^{2}$ ) setzen etwa $2 \mathrm{~mm}$ breite concentrische Ringe zusammen. Die radialen Gruppen der kleinen Gefässe ${ }^{3}$ ) sind meist $0,25-0,5 \mathrm{~mm}$ breit und lieben sich durch hellere Färbung von den gelbbraunen Holzspitzzellen deutlich als. Die Holzstumpfzellen sind in schmalen tangentialen ${ }^{4}$ ) Reihen angeordnet. Die Zahl der letzteren hängt von der Breite des Jrhresringes ab. In schmalen Jahresringen waren etwa 3 , in breiten sogar 20 tangentiale Reihen dieser Zellen zu zählen. - Die 0,5-0,7 mm breiten Markstrahlen ${ }^{5}$ ) stehen horizontal $2-5 \mathrm{~mm}$ ab und sind auf dem Querschnitt heller als die Grundmasse des Holzes. Auf 15 qmm des Tangentialschnitts kommen wie bei Q. lyrata nur 6 Narkstrahlen, die $15-35 \mathrm{~mm}$ hoch sind. Der Radialschnitt zeigt hellbraune oder röthliche Spiegel und feine, ziemlich regelmässige Längsstreifen, die von den tangential angeordneten Stumpfzellen herrühren. Die Jahresringe erscheinen zwischen je zwei breiten Markstrahlen nach der Mitte des Stammes eingesenkt. Der Splint ist hellröthlich, das Kernholz rothbraun. Die Holzspitzzellen sind wie bei den meisten Eichen $1,51 \mathrm{~mm}$ lang und $0,017 \mathrm{~mm}$ breit, ihre Wände $0,0087 \mathrm{~mm}$ dick. ${ }^{6}$ )

Technischer Werth: Nach den äbereinstimmenden Aussagen amerikanischer Botaniker soll das Holz dieser Eiche sehr geschätzt sein. Es findet Verwendung zum Schiffsbau, zu Küferwaaren, Möbelund Wagengeräthschaften, Pfählen u. s. w. -

Dieser stattliche Baum soll 6-8' im Durchmesser haben ${ }^{7}$ ) und findet sich in Neu-Schottland, Neu-Braunschweig, Canada, Florida und Texas.

1) Sargent'sche Holzsammlung 207. Querschnitt auf Fig. 27.

2) Fig. 27 G.

3) Fig. $27 \mathrm{~g}$.

4) Fig. 27 st.

5) Fig. $27 \mathrm{MLI}^{\prime}$.

6) Die Zellen der meisten Eichen weichen in ihren Dimensionen so wenig $a b$, dass ich davon absehen werde, sie näher anzugeben. Ich verweise auf den allgemeinen Theil dieser Arbeit.

7) Sargent: l. c. p. 45. 
3. Quercus Durandii Buck. "Post oak".

Der anatomische Bau weicht in nichts von voriger Art ab. Nur sind die breiten Markstrahlen etwas weniger weit horizontal abstehend. Es kommen auf $15 \mathrm{qmm}$ des Tangentialschnitts 8-10 breite Markstrahlen mit einer Höhe von $16-30 \mathrm{~mm}$. - Jer Radialschnitt zeigt breite weisslichgrane oder bräunlichgelbe Spiegel. I)as Kernholz ist gelbbraun, der Splint gelblichweiss. -

Nach Dr. Engelmann ${ }^{1}$ ) soll das Holz zu Pfosten gebraucht werden, weil es der Fäulniss widersteht.

Vorkommen: Selten; soll nach Dr. Engelmann in Texas zu finden sein.

\section{Quercus stellata Wang. ${ }^{2}$ )} „Post oak“. Syn.: Q. obtusiloba Mich. Q. Durandii?

Die concentrischen Kreise weiter Gefässe bestehen aus 2 Lagen in radialer Richtung. Der radiale Durchmesser der grossen Gefässe beträgt $0,45 \mathrm{~mm}$, ist also bedeutend. In allen Gefässen liessen sich schon mit blossem Auge Thyllen entdecken. Die tangentialen Reihen der Stumpfzellen sind deutlich sichtbar und waren in den schmalen Jahresringen in nur geringer Anzahl $(4-5)$ vorhanden. Die grossen Markstrahlen sind horizontal $1-3 \mathrm{~mm}$ abstehend, meist gelblichbraun gefïrbt. Der Tangentialschnitt zeigt auf $15 \mathrm{qmm} 12$ breite Markstrahlen, die dieselbe horizontale Ausdehnung wie bei Q. alba besitzen, doch betrïgt ilıre Höhe nur $15-20 \mathrm{~mm}$. Der Spiegel ist dunkelbraungelb, der Splint braunroth und das Kernholz zeigt ein ins Gelbliche spielendes Braun. Auch bei dieser Eiche sind die Jahresringe zwischen je zwei breiten Markstrahlen eingesenkt.

T'echnischer. Werth: Nach Engelmann ${ }^{3}$ ) soll das Holz zu Pfosten, nach Loudon sogar zum Schiffsbau Verwendung finden.

Vorkommen: Dieser 50' hohe Baum liebt sandigen Boden in der Nähe der See und findet sich im südlichen Florida, Missouri, Nebraska, Arkansas, Texas.

1) Briefliche Mittheilung an Prof. Caspary.

2) Sargent'sche Holzsammlung Nr. 235.

3) Briefliche Jittheilung an Prof. Caspary. 


\section{Quercus macroearpa Mchx. ${ }^{1}$ )}

„Burr oak, Mossy cup white oak, Over cup oak". Syn : Q. olivaeformis IIchx.

Grosse Gefüsse wie bei voriger. Die hellen Gruppen kleiner Gefässe zeigen in den einzelnen Jahresringen eine zum Radius schiefe Anordnung und sind auf dem (Qnerschnitt baumartig vertheilt. Die Stumpfzellen stehen in breiten undeutlichen tangentialen Streifen zu 13 in $2 \mathrm{~mm}$ breiten Jahresringen. Die breiten Markstrahlen sind horizontal 3-4 $\mathrm{mm}$ abstehend. Thre Farbe ist auf dem Quersehnitt im Kernholz dunkelbraun. Auf 15 qmm des 'Tangentialschnitts kommen 7-15 grosse Markstrahlen, Geren Höhe und Breite von voriger Art wenig verschieden ist. Der Splint ist gelblichbraun, das Kernholz dunkelbraun und schwer zu schneiden. Die Jahresringe sind zwischen den grossen Markstrahlen concav.

Techniseher Werth: Nach Sargent ${ }^{2}$ ) soll das Holz muthmasslich ein gutes Brennmaterial liefern, nach Purshi3) soll es ausgezeichnet sein.

Vorkom men: In Canada, Vermont, Pennsylvanien, Wiscounsin, Nebraska, Kansas. Q. maerocarpa ist ein $60-80^{\prime}$ hoher Baum von 4-8' im Durchmesser.

\section{Quereus Wislizeni Alph. DeC. ${ }^{4}$ )}

Syn : Q. Horehus Kiell.

Die Jahresringe sind durch 2-3 Iagen 0,30 $\mathrm{mm}$ weiter, zu concentrischen Kreisen geordneter, grosser Gefässe deutlich markirt Die radialen Züge kleiner Gefïsse verlaufen im Splint mit parallelen Rändern, siud nieht selten $0,75 \mathrm{~mm}$ breit und von heller Farbe. Zwisehen den 2-2,5 $\mathrm{mm}$ entfernten breiten Markstrahlen befinden sich 1-2 radiale Reihen kleiner Gefässe, die tangential nur selten zur Vereinigung kommen. Die hellen tangentialen Reihen der Stumpfzellen heben sich dentlich ron der dunkleren Umgebung ab. In $3 \mathrm{~mm}$ breiten Jahresringen waren ihrer $10-12$ zu zählen. Auf

1) Sargent'sche Iolzsammlung No. 227.

2) "A catalogue etc." p. 49.

3) Loudon ,Arboretum et fruticetum britannicum " P. 1872.

4) Sargent'sche Molzsammlung No. 239. Eine immergrüne Eiche der Abtheilung Jelanobalanus Eng. 
15 qmm des Tangentialschnitts kommen 25 -30 breite Markstrahlen, deren Höhe 10-20 mm beträgt. - Der Radialschnitt zeigt deutliche gelbliche und gelbbraune Spiegel. Die Längsstreifung ist deutlich und regelmässig. Der Splint ist gelblich, das Kernholz hart und dunkelbraun.

Nach Engelmann ${ }^{1}$ ) soll das Holz dieser Eiche zäh und dauerhaft sein.

Vorkommen: In den Thälern und auf den niedrigeren Gebirgen Californiens. Es soll ein mächtiger Baum von 60' Höhe und 10--18' Umfang sein. ${ }^{2}$ )

\section{Quercus Prinus L. ${ }^{3}$ )}

"Chestnut oak". Syn.: Q. Prinus v. monticola IIchx.

Q. montana Willd.

Die grossen Gefïsse zu vierschichtigen breiten Ringen vereint. Die radialen Gruppen kleiner Gefässe sind im Kernholz radial meist getrennt, im Splint nicht selten rereint. Die Stumpfzellen bilden bestimmt begrenzte, schmale tangentiale Reihen im Herbstholz. Im Frïhlingsholz sind sie mehr oder weniger zerstreut anzutreffen. Die 0,5-0,75 mm breiten Markstrahlen zeigen den Abstand von $3-5 \mathrm{~mm}$ in horizontaler Richtung. Auf $15 \mathrm{qmm}$ des Tangentialschnitts konnte ich 10-12 breite Varkstrahlen finden, deren Höhe nur $10-15 \mathrm{~mm}$ war. - Der Splint erscheint gelblichroth und ist leicht zu schneiden. Das Keruholz ist gelb- bis rothbraun. - Der Radialschnitt zeigt gelblichrothe Spiegel und deutliche Längsstreifung.

Der technische Werth soll unbedeutend sein, weil das Holz zu porös ist. Es wird nur zur Herstellung von Trockengefïssen und Wagen gebraucht. Engelmannt) hält es für ebenso vortrefflich wie das Holz von Q. bicolor Willd.

Vorkommen: In Vermont, bei New-York, im Sïden der Alleghany-Gebirge; in Kentucky und Tennessee spärlich. Ein Baum von mittlerer Grösse.

1) Sereno Watson: „Botany of California“, vol. II, p. 99.

2) Sargent 1. c. p. 52 .

3) Sargent'sche Sammlung No. 514, und ans dem botanischen Garten von St. Petersburg.

4) Briefl. Witth. an Prof. Caspary. 


\section{Quercus Garryana Dougl. ${ }^{1}$ ) \\ Syn.: Q. Neoei Liebm.}

Ringe grosser Gefüsse von 2-3 Schichten zusammengesetzt. Die Stumpfzellen stehen in breiteren und kürzeren tangentialen Reihen. Die grossen Markstrahleu erscheinen auf dem Stammquerschnitt hellgelblich und im Herbsttheil der Jahresringe röthlich, wegen grossen Gehalts an Gerbstoff. Eine ähnliche Erscheinung kann man an den breiten Markstrahlen von Q. Cerris und austriaca wahrnehmen. Der horizontale Abstand der breiten Markstrahlen beträgt $3-4 \mathrm{~mm}$ und auf $15 \mathrm{qmm}$ des tangentialen Schnitts kommen 9 Strahlen, deren IIöhe 25-30, deren Breite $0,75 \mathrm{~mm}$ ist. Die Spiegel sind gelblichbraun, der Splint gelblichgrau und das Kernholz dunkelbraun oder hellrothbraun. Das Ifolz ist leicht zu schneiden und bricht leicht. Die Holzspitzzellen sind im Mittel 1,30 mm lang und $0,0205 \mathrm{~mm}$ breit. Nicht selten fand ich sie in $0,28 \mathrm{~mm}$ lange Zellen getheilt, deren Querwände äusserst zart waren.

Nach Sargent ${ }^{2}$ ) und Engelmann ${ }^{3}$ ) soll das Holz dieser Weisseiche weniger brauchbar sein.

Vorkommen: Britisch-Columbia, südlich von der Franciscobai. Soll von den amerikanischen Eichen am weitesten nach Norden vordringen.

9. Quercus bicolor var. Michauxii Eng. ${ }^{4}$ )

Syn.: Q. Prinus palustris Mehx.

Q. Michauxii Nutt.

Die grossen Gefässe sind reich an Thyllen und bilden 2-3 schichtige concentrische Ringe. Die breiten Reihen kleiner Gefässe sind in den dünnen Jahresringen schief zum Radius angeordnet. Die Stumpfzellen bilden scharf begrenzte schmale tangentiale Reihen, die in $1 \mathrm{~mm}$ breiten Jahresringen zu 12 stehen. Auf $15 \mathrm{qmm}$ des tangentialen Schnitts kommen 7 breite Markstrahlen mit einer Höhe von $10-35 \mathrm{~mm}$ und der Breite ron $0,5 \mathrm{~mm}$. Der Radialschnitt
1) Sargent'sche Sammlung No. 219.
2) l. c. p. 48 .
3) Briefl. Mittheilung.
4) Sargent'sche Sammlung No. 209. 
zeigt eine deutliche Längsstreifung und gelblichbrame Spiegel. Der Splint ist auf dem Querschnitt gelblichroth, das Kernholz braunroth. Das Holz ist weniger compact und leichter, die radialen Züge kleiner Gefässe breiter als bei der eigentlichen Quercus bicolor Willd.

Nach Engelmann's Nittheilung an Professor Caspary soll das Holz vortrefflich sein, wird zur Verfertigung von Wagen und Körben benutzt.

Vorkommen: In Delaware, Illinois und im nördlichen Florida. -

$\beta$ ) Die radialen Zïge enger, kleiner Gefässe sind bedeutend schmäler als in Stämmen voriger Gruppe und erscheinen auf Stammquerschnitten in baumartiger Anordnung. Sehr oft erstrecken sich von der radialen Reihe, von der Mitte des Jahresringes an, zwei neue Züge, die zur Peripherie des Herbstholzes getrennt verlaufen. Eine tangentiale Tereinigung kommt selten vor. In dem dichten, sehr harten Holz der Quercus undulata Torr. var. grisea Liebm. sind die kleinen Gefässe in schmale radiale bogige Reihen angeordnet, die zuweilen in der Mitte des Jahresringes verschmelzen, sich bald wieder trennen und nun wiederum auf eine kurze Strecke vereint anzutreffen sind. Dadurch erhält der Querschnitt ein buntes Aussehen.

\section{Quercus bicolor Willd. ${ }^{1}$ )}

Swamp white oak. Syn.: Q. Prinus var. tomentosa Mchx.

$=\mathrm{Q}$. Prinus var. discolor $\mathrm{I} \mathrm{C} \mathrm{chx}$.

Die Ringe grosser Gefüsse 2-3schichtig. Die Stumpfzellen lassen breite, weniger deutliche tangentiale Streifung bemerken. In $4 \mathrm{~mm}$ breiten Jahresringen befinden sich 7-10 tangentiale Stumpfzellenreihen. Die $0,25-0,5 \mathrm{~mm}$ breiten und $15-30 \mathrm{~mm}$ hohen Markstrahlen stehen horizontal $5-10 \mathrm{~mm}$ ab. Auf $15 \mathrm{qmm}$ des Tangentialschnitts kommen 8 Markstrahlen. 1)ie Spiegel sind gelbbraun, die Streifung des Radialschnittes undeutlich. Der Splint ist weiss, das Ḱernbolz auf dem Querschnitt braun.

Das Holz soll nach Aussagen von Engelmann, Sargent und Loudon an Güte dem von Q. alba nicht nachstehen.

1) Sargent'sche Sammlung No. 209. 
Vorkommen: Diese ausserordentlich grosse Eiche soll $30^{\prime} \mathrm{im}$ Umfang erreichen und findet sich an Flussufern und Sümpfen Canadas, in den nördlichen Distrikten der Vereinigten Staaten, längs dem Alleghany-Gebirge, Georgia, Arkansas, Nebraska.

\section{Quercus sessiliflora Sm. ${ }^{1}$ )}

Trauben- oder Wintereiche. Syn.: Q. Robur var. b. L.

Die grossen Gefüsse bilden breite etwa dreischichtige concentrische Kreise im Frühlingsholz. Die grossen Markstrahlen sind von gleicher Breite wie in dem Holze der vorigen Art. Ihr horizontaler Abstand scheint über $5 \mathrm{~mm} z u$ betragen. Wiesner ${ }^{2}$ ) giebt an, dass sie breiter und weiter ron einander entfernt sind als bei Q. pedunculata. Die Stumpfzellen stehen in schmäleren und breiteren tangentialen Reihen.

Das helle Ilolz dieser Eiche soll den Einwirkungen des Wassers weniger gut widerstehen. ${ }^{3}$ )

Vorkommen: In Süd- und Mittel-Europa, findet sich auch in einigen Theilen unserer Provinz und einige Tarietiiten fehlen auch in Asien nicht. ${ }^{4}$ )

\section{Quercus iberica Stev. ${ }^{5}$ )}

Syn.: Q. sessiliflora var. @. iberica (Stev.) DeC.

Der Durchmesser des von mir untersuchten Stammes war $3,8 \mathrm{~cm}$ gross. Grosse Gefïsse wie bei voriger, doch stehen die kleinen Gefüsse in radialen geschlängelten Reihen. Die Stumpfzellen lassen weniger deutliche, breite, tangentiale Streifen erkennen. Die breiten Markstrahlen stehen horizontal $2-3 \mathrm{~mm}$ ab, sind $0,25-0,5 \mathrm{~mm}$

1) Nach vorzüglichen Schnitten, die mir Professor Caspary gütigst zur Untersuchung übergab. Ich konnte grüssere Stammstücke dieser Eiche uicht erlangen.

2) Rohstoffe p. 605 .

3) Th. Hartig: ,Vollstïndige Naturgeschichte der forstlichen Kulturpflanzen Deutschlands". Loudon: 1. c. p. 1786 u. 1788.

4) Alph. DeCandolle: Prodomus pars XVI, sectio posterior, Fasc. II, p. $6-11$.

5) ex horto berol. 
breit und $10-30 \mathrm{~mm}$ hoch. Auf $15 \mathrm{qmm}$ des tangentialen Sehnitts kommen 9 breite Narkstrahlen.

Nach Alph. 1)e(andolle hesitzt diese Eiche eine grosse Verbreitung. Er giebt sie an für die Strecke von Transkaukasien bis Frankreich. $\left.{ }^{1}\right)$

13. Quercus grosseserrata BI. ${ }^{2}$ ). „Midsu nara". $\beta$. crispula Miq. Ann. mus. Lugd, bat. p. 104.

Die concentrischen Kreise grosser Gefässe nur von 1--2 Lagen gebildet. Die radialen Reihen kleiner Gefässe sind tangential ca. $1 \mathrm{~mm}$ weit abstehend und wenig getheilt. Die Stumpfzellen bilden 4-5 tangentiale schmale Reiheu. Die breiten tiefbraunen Markstrahlen besitzen nahezu dieselbe Vertheilung und Breite wie bei der vorigen Art. Der Splint ist gelblichbraun, das Kernholz tief braunroth. Die Holzspitzzellen sind $0,90 \mathrm{~mm}$ lang und $0,020 \mathrm{~mm}$ im Nittel breit, besitzen zuweilen senkrechte Spaltporen und zeigen $\mathrm{Zwei-}$ spitzigkeit.

Vorkommen: In Japan. ${ }^{3}$ )

\section{Quercus castaneifolia C. A. Mey. $\left.{ }^{4}\right)$}

Die concentrischen Kreise grosser Gefässe zeigen 1-2 Lagen. Die radialen Reihen kleiner Gefässe zeigen in der Mitte der Jahresriuge eine Zweitheilung. Die Reihen der Stumpfzellen lassen eine tangentiale Anordnung erkennen, sind aber undeutlich. Hier wie in voriger Art erscheinen sie auf dem Querschnitt unter dem Mikroskop in kurzen, zuweilen geschlängelteu oder isolirten, auch netzmaschigen tangentialen Binden. Stets werden sie von Holzspitzzellen und Markstrahlen, sowie durch die radialen Züge kleiner Gefässe getrenut.

1) Alph. DeCandolte: Prodrom. par's XVI, sectio post. Fasc. II, p. 10 u. 11.

2) ex museo petrop.

3) Ich konnte nur ein schadhaftes Stammstück dieser von Maximowicz auf Jeso bei Hakodate gesammelten Eiche untersuchen. Ex museo petrop.

4) ex hort. berol. 
Auf $15 \mathrm{qmm}$ d. T.') kommen 8-10 grosse Markstrahlen, deren Höhe $10-15 \mathrm{~mm}$, die Breite $0,25-0,5 \mathrm{~mm}$ und deren horizontaler Abstand nur $2 \mathrm{~mm}$ betrïgt. Der Splint ist hellgelb, das Kernholz grau bis braunroth. - Die grossen Gefässe enthalten zuweilen isodiametrische Thyllen. In engeren Gefüssen waren fast cỵlindrische Thyllen zu bemerken. ${ }^{2}$ ) Auch hier waren die $0,60 \mathrm{~mm}$ langen Spitzzellen nicht selten gabelig getheilt. Das Holz ist hart und zähe.

Vorkommen: Ein mittelgrosser Baum der südlichen Vorberge des Kaukasus. Nach Kotschy ${ }^{3}$ ) wurde diese Eichenart 1861 von Cossa in Kabylien und von Odon Debeaux auch bei Pei-ho im östlichen China gefunten. Das untersuchte Stammstïck erhielt die Sammlung des königsberger botan. Gartens aus dem berliner Königl. botan. Garten.

15. Quercus pedunculata Ehrh.

Stiel- oder Sommereiche. Syn.: Q. Rubur L. sp. pl.

Die concentrischen Kreise grosser Gefässe sind aus 2-3 Schichten zusammengesetz.t. Die radialen Züge kleiner Gef̈̈sse sind sehr schmal. Sie theilen sich in der Mitte des Jahresringes und gewähren damn in der Aufsicht des Querschnitts das Bild eines Y. Seltener kommen einfache radiale Reihen vor. - Die Stumpfzellen stehen in lockeren, längeren und kürzeren tangentialen Reihen. Die breiten Markstrahlen stehen $2-4 \mathrm{~mm}$ ab, sind im Splint etwas gelblich, im Kernholz bräunlich gefürbt. Der tangentiale Schnitt zeigt anf 15 qmm 10-20 und mehr Markstrahlen, deren Höhe $5-25$ mm, die Breite $0,25-0,75 \mathrm{~mm}$ betragen kann. Im Kernholz bemerkt man grosse gelbbraune Spiegel. Die Längsstreifung ist auf dem radialen Schnitt kaum zu bemerken. Das Auftreten der Stumpfzellen mit seitlichen Fortsätzen habe ich bereits im allgemeinen Theil erwähnt und will darauf nicht mehr zurückkommen.

Nach Th. Hartig soll das Holz etwas dunkler und danerhafter sein als das der Q. sessillora. Es wird zu den mannigfachsten Ge-

1) Ich werde diese Bezeichnung für den tangentialen Schnitt von jetzt ab immer gebrauchen.

2) In macerirtem Material.

3) Kotschy: Die Eichen Europas und des Orients, No. 49. 
räthsehaften verarbeitet und eignet sich zum Schiffsbau mebr als die soeben erwähnte Art. Das Holz erhält sich im Wasser sehr gut und wird hierin fast noch dauerhafter. ${ }^{1}$ )

Vorkommen: In ganz Europa; bildet nach Kotsehy ${ }^{2}$ ) noch bei Archangel Bestände und ist auch in unserer Provinz die häufigste Eichenart.

\author{
16. Quercus Thomasii Ten. ${ }^{3}$ ) \\ Syn.: Q. Robur var. Thomasii Alph. DeC. \\ Q. brutia Ten. \\ Q. pedunculata macrocarpa Bess. \\ Q. Itaas Kotschy (nach Koch).
}

Der untersuchte Stamm hatte einen Durchmesser von $3,7 \mathrm{~cm}$, gehörte also einem jungen Exemplar an. Die grossen Gefässe stehen tangential weit ab, liessen jedoch eine Anordnung zu concentrischen Kreisen im Frühlingsholz erkennen. Die kleinen Gefässe gewährten auf dem Quersehnitt in ihrer radialen Anordnung ein baumartiges Aussehen und die bereits erwähnte Y-Form. Dic Stumpfzellen waren theils in breiten und theils in sehmalen compacten tangentialen Reihen zu bemerken. Die breiten Markstrahlen sind horizontal 2-3 $\mathrm{mm}$ entfernt, $2-5 \mathrm{~mm}$ hoch und $0,25 \mathrm{~mm}$ breit. Auf $15 \mathrm{qmm}$ d. T. fand ich deren 24. Das Holz ist rothbraun und dicht, da in ihm die weitlichtigen Zellen und Gefüsse weniger häufig als die dickwandigen Holzspitzzellen sind.

1) Von Professor Caspary erhielt ich ein ron gerbsaurem Eisen geschwärztes Stammstück einer Eiche, die in einem für römischen Ursprungs gehaltenen, 1856 aufgefundenen, unterirdischen Bau von Frechem bei Köln gefunden worden war. Ich fertigte Schnitte an, die durch concentrirte Salpetersäure sich röllig klären liessen und erkannte nun in denselben den anatomischen Bau der beschriebenen Q. pedunculata wierler. Die grossen Gefässe bilden concentr. Krreise von wenigen Lagen. Die radialen Gefïsszïge sind schmal und gewähren ein $\mathrm{Y}$-artiges Bild; zuweilen waren sie in einfachen radialen Reihen angeordnet. Die Vertheilung . und Anordnung der Stumpfzellen und Jarkstrablen fand ich genau so wig bei Q. pedunculata, so dass ich nicht umhin kann, das fragliche Holz als dicser Art zugehörig zu betrachten. Abgesehen von anatomischen Merkmalen würde schon die Dauerhaftigkeit des Holzes einen Fingerzeig geben, welcher Art es angehört.

2) 1. c. No. 27.

3) ex hort. berol. 
Vorkommen: In Süd-Frankreich und Unter-Italien, am Bosporus und in Taurien. ${ }^{1}$ ).

\section{Quercus undulata var. grisea Eng. ${ }^{2}$ )}

„Rocky mountain scrub oak“. Syn.: Q. grisea Liebm.

Die grossen Gefässe sind wie bei voriger Art angeordnet. Die radialen Züge kleiner Céfässe zeigen auf dem Querselmitt einen geschlängelten Verlauf, verschmelzen hin und wieder auf kurze Strecken mitten im Jahresringe und trennen sich wieder. Im sehr festen und harten Kernhol\% sind sie fast bis zum Verschwinden schmal. Die tangentialen Reihen der Stumpfzellen sind undeutlich durch Dazwischentreten vieler Holzspitzzellen. Letztere besitzen bei einer Länge von $1 \mathrm{~mm}$ ein sehr enges, in vielen Fällen unmessbares Lumen und ihre Wände sind 0,009-0,01 mm dick. Der tangentiale Durchmesser der grossen Gefässe ist $0,012-0,23 \mathrm{~mm}$ gross, während der radiale nur $0,16 \mathrm{~mm}$ beträgt. Die $0,5--0,75 \mathrm{~mm}$ breiten Markstrahlen fand ich $5 \mathrm{~mm}$ hoch und tangential $2-3 \mathrm{~mm}$ abstehend. Auf 15 qmm d. T. kommen 30-40 breite Markstrahlen, deren Farbe in Kernholz graugelb, im Splint fast rein weiss ist. Ersteres ist tief gelbbraun, letzterer grauröthlich. Der radiale Schnitt zeigt grosse gelbbraune Spiegel; eine regelmässige Längsstreifung konnte ich auf ihm nicht wahrnehmen.

Vorkommen: Diese Eiche ist strauchartig und soll an den östlichen Schluchten der Rocky-Mountains in vielen Formen anzutreflen sein. Ausserdem wird sie für Neu-Mexiko, Texas, Utah und Californien angegeben (Sargent: „A Catalogue“ p. 52).

18. Quercus mongolica Fisch. ${ }^{3}$ )

Syu.: Q. Robur Pall.

Die grossen Gefässe sind in den concentrischen Kreiseı in 2 Lagen anzutreffen. Die radialen Reihen kleiner Gefïsse stehen ca. $1 \mathrm{~mm}$ ab. Die Stumpfzellen setzen lockere tangentiale Reihen

1) DeCandolle: Prodromus, Fase. II. p. 5.

2) Sargent'sche Sammlung No. 237 v. 6.

3) ex museo petrop. 
zusammen. Die $0,5-0,75 \mathrm{~mm}$ breiten Markstrahlen sind $4-10 \mathrm{~mm}$ hoch und horizontal $3 \mathrm{~mm}$ abstehend. Auf $15 \mathrm{qmm}$ d. T. kommen etwa 13 breite Markstrahlen. Die Radialschnitte lassen zwar breite Spiegel, aber keine deutliche Längsstreifen erkennen. Das braungelbe Holz ist schwer und hart wie bei voriger Art.

Torkommen: Nach Alph. DeCandolle') findet sich dieser niedrigo Baum²) in Dahurien an den Flïssen Argun und Amur, ferner in der Mandschurei an der Talicwhan-Bai.

\section{Quercus macranthera Fisch. et Mey. ${ }^{3}$ )}

Syn.: Q. pubescens Szovits.

Grosse Gefïsse wie bei Q. castaneifolia. Die radialen Reihen kleiner Crefässe sind sclımal, schlängelnd und etwas schief zum Verlauf der Markstrahlen angeordnet. Die Stumpfzellen bilden schmale radial regelmässig abstelıende tangentiale Reihen. Daher ist auch der radiale Schnitt deutlich längsstreifig. Im Frühlingsholz der Jahresringe sind die tangentialen Reilien der Stumpfzellen locker und daher mit blossem Auge weniger deutlich bemerkbar. Die Markstrahlen sind $0,5 \mathrm{~mm}$ breit, $5-25 \mathrm{~mm}$ hoch und auf $15 \mathrm{qmm}$ d. T. etwa 18 anzutreffen. Das Holz ist zähe und riemlich fest. Der untersuchte Stamm mass 3,5 cm im Durchmesser und war nur von hellgelbem Splint gebildet. Auch die Markstrahlen waren auf dem Querschnitt hellgelb.

Vorkommen: In deu Wäldern des kaukasischen Georgiens. ${ }^{4}$ )

20. Quercus heterophylla Mchx. ${ }^{5}$ )

„Bartram oak". Syn.: Q. aquatica var. heterophylla AIph. DeC.

Q. Phellos + coccinea Eng.

Q. Phellos + tinctoria? A. Gray.

Q. aquatica Mehan.

Jahresringe durch eine Lage grosser Gefässe begrenzt, deren tangentialer Durchmesser $0,26 \mathrm{~mm}$ und der radiale $0,20 \mathrm{~mm}$ gross

1) Prodromus system. nat., Fase. II.

2) Loudon: 1. c. p. 1932.

3) ex hort. berol.

4) Alph. DeCandolle: Prodrom. system. nat, Fasc. Ir, p. 13.

5) es museo petrop. 
ist. Die Jahresringe sind schmal, die radialen Reihen kleiner Gefässe schief zum Verlauf der Markstrahlen angeordnet. Die Stumpfzellen stehen in schmaler tangentialen Reihen, die verschiedene Länge zeigen. In $1 \mathrm{~mm}$ breiten Jahresringen konnte ich $3-7$ Reihen vorfinden. Die $0,5-0,75 \mathrm{~mm}$ breiten Markstrahlen sind $5-11 \mathrm{~mm}$ hoch und zu 12 auf $15 \mathrm{qmm}$ d. T. anzutreffen. In dem Holz dieser Eiche fand ich die schmalsten Holzspitzzellen. Dieselben waren nur $0,008-0,013 \mathrm{~mm}$ breit bei der gewöhnlichen Länge von $1,3 \mathrm{~mm}$. Nicht zu selten waren sie zweispitzig anzutreffen. - Das Kernholz ist braunroth und sehr hart, der Splint ist lrellröthlich mit einem gelblichen Anflug.

Vorkommen: Das erste Exemplar wurde 1750 von Michaux in Pennsylvanien an der Küste Shuylkill in der Nähe von Philadelphia auf dem Felde eines gewissen Bartram gefunden, aber erst zwischen 1810 und 1813 von Michaux beschrieben. Diese Eiche wird von einigen amerikanischen Botanikern fïr einen Bastard gehalten. - Sie soll sich mach Sargent in Delaware, Nord-Carolina und im östlichen Texas vorfiuden.

y) Die grossen Gefässe setzen, im Ganzen betrachtet, im Frühlingsholz der Jahresringe concentrische Kreise zusammen, aber man kann unter ihnen bereits eine radiale Gruppirung dentlich bemerken. Meist schliesst sich eine Gruppe grosser Gefässe an die radiale Reihe kleiner Gefässe, im Ilerbstholz des jüngeren Jahresringes gelegen, an. Nach der verschiedenen Lage der Gefässe im Jahresring liessen sich folgende Unterschiede in der Weite an ihnen feststellen:

In Frühlingsholz

$0,30-0,35 \mathrm{~mm}$ weite Gef.

- mittleren Theil d. Ringes $0,15-0,20$

- Herbstholz $0,04-0,06$

Die Gefässe des mittleren Theils des Jahresringes sind mit blossem Auge wahrnehmbar. Die radialen Reihen engerer Gefüsse sind tangential völlig isolirt durch $0,5-0,75 \mathrm{~mm}$ breite Schichten von Iolzspitz- und Holzstumpfzellen. Sie sind meist parallel dem Verlauf der Markstrahlen angeordnet und weichen nur sehr selten von dieser Richtung ab. In der Mehrzahl sind sie auf dem Querschnitt als einfache, ungetheilte schmale lielle Streifen zu bemerken, die theils durch die ganze Breite des Jahresringes, theils aber erst 
in dessen mittleren Zellschichten beginnend, zur Peripherie verlaufen. Diese Gruppe schliesst sich bereits eng an die folgende, doch fehlen ihren Arten noch die dünnwandigen Gefässe.

\section{Quereus lobata Née. ${ }^{1}$ ) Syn.: Q. Findsii Benth. \\ Q. Ransomi Kellogg.}

Grosse Gefässe in radial gestreckten Gruppen zn 5-9 beisammen. Die Lumina erscheinen oval oder elliptisch, da die Gefässe seitlich zusammengedrückt sind. Ihr Durchmesser in der Richtung der Tangente beträgt $0,23 \mathrm{~mm}$, in der des Radius $0,35 \mathrm{~mm}$. Nur hin und wieder ist im Herbstholz eine Theilung der radialen Züge kleiner Gefïsse zu bemerken, doch vereinigen sich dio Theilreihen an der Peripherie des Jahresringes zuweilen und umsehliessen somit eine inselartige Gruppe von Holzzellen. Die Stumpfzellen lassen im Allgemeinen eine tangentiale Anordnung erkennen, doch kommen sie nur in kürzeren oder längeren tangentialen Gruppen allseitig von Holzspitzzellen umgeben vor. Auf dem Querschnitt erscheinen sie durch das Mikroskop betrachtet in ihrer Anordnung maschig und vereiuzelt. Auf dem Radialschnitt lässt sich keine Längsstreifung in regelmässigen Abständen wahrnehmen. Die Markstrahlen sind $0,5-0,75 \mathrm{~mm}$ breit und $10-30 \mathrm{~mm}$ hoch. Auf $15 \mathrm{qmm} \mathrm{d.} \mathrm{T.}$ kommen etwa 9 breite Markstrahlen. Hieran ist das Holz dieser Eichenart von ien ähnlichen Stämmen der Q. Prinus und Phellos zu unterscheiden. Erstere Art besitzt niedrigere und schmalere, letztere jedoch dichter stehende Markstrahlen. Es ist ausserdem mikroskopisch durch die Beschaffenheit der Gefässwände verschieden. Bei Q. Prinus sind die Jahresringe zwischen je 2 breiten Markstrahlen concav, bei Q. lobata convex hervorgetrieben. Das Kernholz ist braungelb mit einem Anflug von roth. Der Splint ist gelblichroth bis bräunlich.

Nach Engelmann soll das Holz brüchig sein. Es spaltet leicht durch die radialen Reihen der Gefässe und durch die breiten Markstıahlen. Die Jahresringe sind fast $1 \mathrm{~cm}$ breit.

1) Sargent'sche Sammlung No. 225. 
Vorkommen: In Califurnion. Q. lobata soll bis $100^{\prime}$ hoch werden und ihr Stamm 15-20' im Umfang messen.')

\section{Quercus glandulifera $B J_{.}{ }^{2}$ )}

Die grossen (iefässe stehen in Gruppen zn 2-4 im Frühlingsholz, wo sic in Stamme concentrische Kreise zusammensetzen. Die radialen Reihen der engeren Gefässe sind schmal und theilen sich öfter als bei voriger Art. Die tangentialen Reihen der Stumpfzellen sind schmal und dicht, lassen sich daher leicht mit blossem Auge erkennen. Es sind ihrer etwa 10 in $4 \mathrm{~mm}$ breiten Jahresringen vorhanden. Der Radialschnitt zeigt eine regelmässige, dentlich ausgeprägte Längsstreifung. Die Reihen der Holzstumpfzellen sind im dichteren Herbstholz schmaler als im lockeren Frühlingsholz, doch das ist eine gewöhnliche Erscheinung. In ihnen war sehr viel Stärke zu finden, die auch den Narkstrahlzellen nicht fehlte. Die $0,25-0,40 \mathrm{~mm}$ breiten Markstrahlen sind nur $5 \mathrm{~mm}$ hoch und haben einen horizontalen Abstaud von nahezu $5 \mathrm{~mm}$. Sie sind auf $15 \mathrm{qmm}$ d. T. zu 7 vertheilt. Das Holz ron (q. glandulifera gleicht dem dor (Q. aquatica und Catesbaci, unterscheidet sich aber durch die Vertheilung und Grösse der breiten Markstrahlen. -

Das Holz ist auf dem Querschnitt durchweg chocoladefarben (braunroth) wie das Holz der meisten anderen japanesischen Eichen.

Vorkommen: In Japan. ${ }^{3}$ )

II. Die Wände der engen kleinen und zum 'Theil auch die der grossen Gefässe sind 0,0060-0,0080 $\mathrm{mm}$ breit. Ihre Lumina sind auf dem Quersehnitt vollkommen rund oder elliptisch. Die grossen Gefässe in schmäleren und breiteren concentrischen Kreisen zeigen mehr oder weniger radiale Gruppirung.

a) Die concentrischen Kreise grosser Gefässe lassen eine radiale Gruppirung nur undeutlich erkennen. Die kleinen, engen Gefässe stehen in schmalen hellen schlängelnden Reihen und Gruppen in der Richtung des Radius angeordnet.

1) Sargent: 1. c. p. 49.

2) ex museo petrop.

3) Der untersuchte Stamm aus dem petersburger IIuseum wurde von Maximowicz bei Hakodate gefunden. 
23. Quercus rubra L. ${ }^{1}$ )

"Red oak".

Die grossen Gefässe sind in den concentrischen Kreisen meist in 3 Schichten zu bemerken. Einige sind in radialer Anordnung bis fast zur Mitte des Jahresinges angeordnet. Ihr tangentialer Durchmesser ist kürzer als der radiale $(0,25: 0,30 \mathrm{~mm})$. Die breiten Markstrahlen besitzen nur geringe horizontale Abstïnde von 2-3 mm. Ihre Breite ist schr gering, etwa $0,25-0,40 \mathrm{~mm}$, und auch die Höhe übersteigt nicht $10 \mathrm{~mm}$, so dass auf 15 qmm d. 'T. 15-20 Markstrahlen kummen. - Die tangentialen Reihen der Stumpfzellen sind schmal, aber weniger deutlich als auf den Querschnitten der folgenden Art. Auf $4 \mathrm{~mm}$ breite Jahresringe kommen etwa 15 Stumpfzellenreihen. Der radiale Schnitt ist nicht schr deutlich lïngsstreifig. Der Spiegel ist gelbbraun, nicht breit. Das Kernholz ist hellroth mit bräunlichem Anflug. Der Splint ist gelblichweiss mit ciner Beimischung von roth.

Technischer Werth: Das Holz soll nach Sargent nach den Standorten des Baumes scine Dichte ändern nnd damit anch seine Brauchbarkeit. Genannter Autor bemerkt auf Seite 51 seines Catalogs: "Wood varying remarkably in different localities; at the east reddish, porous, light, not durable, principially employed in cooperage; in Northern Wiscounsin and Ilinnesota heavier, durable, compact, and quite generally used in construction".

Diese Aussage wird auch durch eine Mittheilung Engelmann's an Professor Caspary zum Theil bestätigt.

Vorkommen: In allen grösseren Waldungen Nord-Amerikas und dringt wie Q. Garryana am weitesten nach Norden vur.

\section{Quercus tinctoria Bartr. $\left.{ }^{2}\right)$}

"Black oak". "Yellow barked oak". Syn.: Q. nigra Marsh.

Q. velutina Lam.

Q. coccinea v. tinctoria Gray.

Grosse Gefässe wie bei voriger Art angeordnet, nur ist bei ihnen der radiale Durchmesser etwas kleiner als der tangentiale

1) Hierher gehört auch die Q. rubra var. texana Buckl., deren breite Markstrahlen nur $5 \mathrm{~mm}$ hoch sind. Sargent'sche Sammlung Nr. 234.

2) Sargent'sche Sammlung No. 236. 
(r $0,30:$ t 0,39 ). Die schmalen hellen radialen Reihen kleiner Gefässe sind zuweilen nicht durch die ganze Breite des Jahresringes angeordnet. Die Stumpfzellen stehen in schmalen dichten Reihen, welche parallel der Anordnung grosser Gefässe zu concentrischen Kreisen sich vereinen. Ibre regelmässige Anordnung verursacht dic deutlichen Längsstreifen des Radialschnitts. Die $0,5-1 \mathrm{~mm}$ breiten grossen Markstrahlen stehen horizontal $1,5-2 \mathrm{~mm}$ ab, sind $7-10 \mathrm{~mm}$ hoch und auf $15 \mathrm{qmm}$ d. T. zu $15-18$ vertheilt. Das Holz ist hart und zeigt breite rothbraune Spiegel. Das Kernholz ist hellroth, der Splint grauroth.

Techuischer Werth. Das Folz ist geschätzter als das der anderen amerikanischen. Schwarzeichen, die ich zur II. Gruppe stellte. $\left.{ }^{1}\right)$ Wagenbauer und Böttcher verarbeiten es.

Diese $80-100^{\prime}$ hohe und $4-5^{\prime}$ im Durchmesser haltende Eiche soll in allen amerikanischen atlantischen Forsten gemein sein.

ß) Grosse Gefässe undeutlich radial gruppirt. Dio kleinen Gefässe mehr oder weniger deutlich mit blossem Auge wahruehmbar, stehen in tangential getrennten radialen Ciruppen oder Zügen angeordnet.

25. Quercus imbricaria Mchx. ${ }^{2}$ ) „Shingle oak". „Laurel oak". Syn.: Q. latifolia Hort.

Grosse Gefässe, reichlich Thyllen enthaltend, bilden breite 3-4 schichtige Kreise. Die rarlialen Reihen kleiner Gefässe sind im Kernholz schmaler als im Splint. Hier erscheinen sie auf dem Querschnitt als helle Streifen mit parallelen Rändern wie bei Q. Wislizeni. Die einzelnen kleinen Gefüsse sind mit blossem Auge noch nicht dentlich wahrnehmbar. Die Stumpfzellen stehen dicht in tangentialen Reihen und verursachen eine deutliche Streifung des Radialschnitts. Die $0,5 \mathrm{~mm}$ breiten Narkstrahlen sind $5-10 \mathrm{~mm}$ hoch, auf 15 ymm d. T. zu 17 stehend. Vom Gerbstoffgehalt er-

1) Die Rinde wird wegen ibren Gehalts an Quercitrin $\mathrm{C}_{36} \mathrm{H}_{38} \mathrm{O}_{20}$ sebr geschätzt und unter dem Namen "Quercitron" hauptsächlich von Philadelphia aus exportirt. Ausserdem besitzt die Rinde reichlich Gerbstoff.

2) ex museo petrop. 
scheinen sie am Schlusse jedes Jahresringes wie bei der folgenden Art rothgefärbt. Die Spiegel sind im rothbraunen Kernholz roth, im gelblichrothen Splint hellgelb. Das Holz dient zu Brennmaterial.

Vorkommen: Ein kleiner Baum, del westlich ron den Alleghany-Mountains am häufigsten angetrofien wird.

\section{Quercus hypoleuca Engelm. ${ }^{1}$ ) Syn.: Q. confertifolia Torr.}

Jahresringe durch 1-2 Lagen 0,25-0,30 $\mathrm{mm}$ weite Gefässe dentlich begrenzt. Die kleinen Gefïsse in derselben Anorinung wie bei voriger Eiche, im Mittel $0,9 \mathrm{~mm}$ weit. Die Stumpfzellen stehen dicht in längeren und kürzeren tangentialen Reihen, welche verschiedene Breite besitzen. Die grossen Markstrahlen haben einen tangentialen Abstand ron 2 -3 mm, sind 0,5-1 mm breit, 5-13 mm hoch. Ich konnte auf $15 \mathrm{qmm}$ (l. 'T. etwa 13 Strahlen rorfinden. Jer Splint ist gellichroth, das Kernholz ist dunkelroth bis brann. Die Spiegel sind wie bei voriger Art gefïrbt.

Die Verwerthung des Holzes ist mir unbekannt.

Torkommen: Eine $30^{\prime}$ hohe Eiche, deren Stamm 1'Durchmesser haben soll. Sie Wurle von Dr. Rothrock im südlichen Arizona 1874 gefunden, später wurde sie auch anf den San FranciscoMountains entleckt. ${ }^{2}$ )

\section{Quercus laurifolia Mchx. ${ }^{3}$ )}

"Laurel oak". Syn.: G. aquatica var. laurifolia Alph DeC.

Q. Phellos var. laurifolia Chap.

Die grossen Gefässe ganz wie im Holze voriger Eichenart. Die kleinen Gefässe sind $0,12 \mathrm{~mm}$ weit, mit blossem Auge wahrnehmbar und in derselben Anordnung wie bei Q. hypolenca. Die tangentialen Reihen der Stumpfzellen sind parallel den Grenzzellen der Jahresringe angeorlnet. Die Jahresinge erscheinen zwischen den Markstrahlen einwärts gebogen, concav zur Peripherie. Nach Entfernung

1) Sargent'sche Sammlung No. 221.

2) Sargent: l. c. p. 48.

3) Sargent'sche Sammlung No. 221. 
der Rinde findet man das $H_{0} \mathrm{l} z$ an den Rändern der breiten Markstrahlen scharf aufgeworfen. Die 0,75-1 mm breiten Markstrahlen stehen horizontal 2-3 mm ab, sind $5-12 \mathrm{~mm}$ hoch und zu 16 auf $15 \mathrm{qmm} \mathrm{d}$. T. vertheilt. 1)as röthliche Holz ist hart und fest, die Spiegel sind gross und rothbraun.

Technischer Werth: Nach Michaux sen. soll das Holz werthvoll sein und sich zum Schiffbau eignen.

Vorkommen: In den niedriger gelegenen Theilen Nori-Carolinas und im südlichen Florida. Ein grosser Baum von 60-70' Höhe.

\section{Quercus Kelloggii Newb. $\left.{ }^{1}\right)$. \\ Syn.: Q. sonomensis Benth. \\ Q. rubra Benth. \\ Q tinctoria var. californica Torr.}

Die grossen Gefüsse begrenzen in wenigen, höchstens 2 Schichten die Jahresringe. Die kleinen Gefüsse sind $0,10 \mathrm{nmm}$ weit und mit blossem Auge wahrnehmbar. Ihre radialen Reihen sind schmal, werden nur von einer einzigen Reihe von Gefässen gebildet, welche tangential etwa $1 \mathrm{~mm}$ von einander abstehen. Die Stumpfzellen stehen wie die grossen Gefïsse in concentrischen Kreisen, die durch Holzspitzzellen scharf begrenzt werden. Die radialen Schnitte zeigen Längsstreifen in regelmässigen Abständen. Die grossen Markstrahlen erreichen kaum die Breite von $0,5 \mathrm{~mm}$, sind $5-15 \mathrm{~mm}$ hoch und es kommen von ihnen je 22 auf $15 \mathrm{qmm}$ d. T. Das Kernholz ist rothgelb und erinnert an Q. imbricaria. Der Splint ist gelblichweiss gefärbt.

Ueber die Verwerthung des Holzes konnte ich keinen Aufschluss bekommen. Sargent ${ }^{2}$ ) bemerkt nur, dass diese Eichenart sowohl baum- als auch strauchartig auf den Gebirgen Californiens angetroffen wird. Die obige Beschreibung des Holzstammes bezieht sich auf ein baumartiges Exemplar. Das Stammholz strauchartiger Eichen pflegt härter zu sein, auch sind die Gefässgruppen schmaler.

1) Dr. Newberry's name honoring the indefatigable botanical pioneer of Califomia has a priority of seven years." Sereno Watson, Botany of Calif., vol. II. p. 99. - Ex museo petrop.

2) 1. c. p. 49 . 
29. Quercus palustris Mchx. ${ }^{1}$ )

„Pin oak". „Swamp spanish oak“. Sgn: Q. palustris Du Roi, Willd.

Q. montana Lodd. (1836).

Q. Banisteri Lodd.

Die grossen Gefässe begrenzen in einer, seltener in 2 Schichten die schmalen, kaum $1 \mathrm{~mm}$ breiten Jahresringe. Die Gruppen der kleinen Gefässe sind meist schief zum Verlauf der Markstrahlen angeordnet; recht oft gehen sie nicht durch die ganze Breite des Jahresringes. Ihre Weite ist nicht beträchtlich $(0,7 \mathrm{~mm})$ und ihre Lumina mit blossem Ange kaum zu bemerken. Zuweilen sind die kleinen Gefässe ganz isolirt oder nur in sehr geringer Anzahl anzutreffen. Die Stumpfzellen bilden schmale, 1-2 Zellen breite Kreisringe, die mit denen der grossen Gefässe concentrisch sind. In einem Jahresring befinden sich 4-5 solcher Kreise von Stumpfzellen. Der Radialschnitt zeigt eine regelmässige Längsstreifung. Die Holzspitzzellen sind $0,015 \mathrm{~mm}$ im Mittel breit, doch sind ihre Wände im Verhältniss zu denselben Zellen anderer Arten dünn zu nennen (0,0041 mm). Die grossen Markstrahlen laben einen tangentialen Abstand von 2-3 mm, sind $0,25-0,5 \mathrm{~mm}$ breit, $7-15 \mathrm{~mm}$ hoch und zu 15 auf 15 qmm d. 'T. zu finden. Das Kernholz ist hart, tief braunroth, fast schwärzlich. Der Splint ist hellrothbrann.

Technischer Werth: Das Holz soll wenig danerhaft sein, doch soll es nach Loudon²) zu Achsen (Wellen) für Mühlräder (axles of mill-wheels) gebraucht werden.

Vorkommen: Q. palustris ist ein Baum mittlerer Grösse und wächst anf Long-Island, in Connecticut, Nebraska, Kansas und Texas auf niedrigem Grunde.

1) ex hort. berol. et petrop.

2) Loudon: Arboretum et frueticetum brit., p. 1887. 


\section{Quercus falcata M(chx. ${ }^{1}$ )}

"Spanish oak". "Red oak" in Georgia. Syn.: Q. elongata Willd.

Q. discolor v. foliata Spach.

Q. triboba Hchx.

Q. falcata v. triloba DeC.

Die grossen Gefässe wie bei voriger Art, nur sind sie etwas

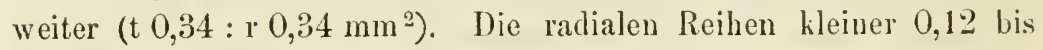
$0,15 \mathrm{~mm}$ weiter Gefässe sind schmal, höchstens 2 schichtig und stehen tangential $0,75-1 \mathrm{~mm}$ ab. Die Stumpfzellen sind theils zu concentrischen Kreisen, theils zu längeren und kürzeren tangentialen Reihen von geringer Breite angeordnet. In $2 \mathrm{~mm}$ breiten Jahresringen befinden sich etwa 10 Stumpfzellreihen. Die braunrothen grossen Markstrahlen stehen horizontal etwa $2-2,5 \mathrm{~mm} \mathrm{ab}$, sind 5-15 $\mathrm{mm}$ hoch, 0,3 $\mathrm{mm}$ breit, und es stehen ihrer $15-17$ auf $15 \mathrm{qmm}$ d. T. Das Holz ist leicht, gleicht etwas dem von Q. rubra, besonders aber der folgenlen Art, von denen es sicls durch die angegebenen Merkmale unterscheiden lässt. Del Splint ist tief braunroth, das Kernholz ist roth. Der radiale Schnitt ist regelmässig längsstreifig.

Technischer Werth: Gering, da das Holz nicht danerhaft ist; wird von Böttchern zu Trockengefässen verarbeitet. ${ }^{3}$ )

Verbreitung: Nach Sargent ${ }^{4}$ ) ist diese Art in den südlichen atlantischen Staaten von Nord-Amerika sehr gemein und ist in den mittleren Districten der vorwiegendste Waldbaum.

\section{Quercus (atesbaei Mchx.5.}

„Turkey oak“. „Scrub oak“. „Forked-leaf black Jack“.

Syn.: Q. rubra $\beta$ Abb. et $\mathrm{Sm}$.

Die grossen, reich mit Thỵllen erfüllten Gefüsse sind radial $0,25-0,31 \mathrm{~mm}$, tangential $0,29-0,42 \mathrm{~mm}$ weit, und setzen breite 3 schichtige Ringe zusammen. Die kleinen Gefässe sind $0,15-0,20 \mathrm{~mm}$

1) Sargent'sche Sammlung No. 218.

2) $\mathrm{t}=$ tangential, $\mathrm{r}=$ radial.

3) Die Rinde soll reich an Gerbstofi sein und wird deshalb nach Michaux fil. sehr geschätzt.

4) l. c. p. 48 .

5) Sargent'sche Sammlung Nr. 210. 
weit, mit blossem Auge sichtbar und stehen meist in 2-3schichtigen radialen Reihen. Zuweilen sind sie anch gänzlich isolirt unter den Ifolzzellen anzutreffen. Die Reihen der Stumpfzellen sind etwas schlängehnd, aber wie gewöhnlich tangential angeordnet. Doch stehen sie niclst dicht gedrängt, sondern sie sind durch Holzspitzzellen isolirt in längeren und kürzeren Reihen anzutreffen. Sie verursachen dennoch anf dem radialen Schnitt eine bemerkliche Längsstreifung.

Auch hier sind die Jahresringe zwischen den Markstrahlen eingebogen. Letztere sind bei einer Breite von $0,5-0,75 \mathrm{~mm}$ horizontal 2-4 $\mathrm{mm}$ von einander entfernt, 5-8 $\mathrm{mm}$ hoch und je 13 auf $15 \mathrm{qmm}$ d. T. Ihre Farbe ist auf dem Stammquerschnitt lichtbraun. Der Spiegel erscheint rothbraun, las Kernholz ist von gleicher Farbe, während die Splintlagen mehr gelblichroth aussehen.

Technischer Werth: Gering; das leichte weiche Holz wird nur als Brennmaterial gebraucht. ${ }^{1}$ )

Vorkommen: Eine kleine, nur 25' hohe Eiche an den sandigen Gestaden von Nord-Carolina, Florida und Süd-Alabama.

32. Quercus aquatica Nutt. ${ }^{2}$ )

"Water oak". Syn.: Q. nigra Willd.

Q. uliginosa Wang.

Die grossen Gefässe sind seitlich zusammengedrückt (tangential $0,14-0,28 \mathrm{~mm}$, radial $0,28 \mathrm{~mm}$ weit) und setzen in 5 Lagen breite Ringe zusammen. Eine radiale Anordnung derselben wird theilweise durch dazwischentretende breite Markstrahlen hervorgerufen. Die kleinen Gefässe besitzen nahezu die Weite und Anordnung wie im Stamme der Q. Catesbaei. Die tangentialen Reihen der Holzstumpfzellen sind durch dazwischenstehende Holzspitzzellen sehr gelockert und gewähren auf dem Querschnitt kein deutliches Bild; mit dem Mikroskop betrachtet erscheint ihre Auordnung maschig. Die Fläche des Radialschnitts zeigt keine regelmässige deutliche Streifen. Die grossen Markstrahlen sind $0,5-0,75 \mathrm{~mm}$ breit, 5-10 $\mathrm{mm}$ hoch, horizontal $1-2 \mathrm{~mm}$ abstehend und zu 12 auf 15 qmm d. T. vertheilt.

1) Sargent: 1. c. p. 46.

2) Sargent'sche Sammlung No. 208. 
Die Hol\%spitzzellen sind 2,043 $\mathrm{mm}$ im Mittel lang, $0,10 \mathrm{~mm}$ breit und besitzen ein Lumen von 0,001-0,002 $\mathrm{mm}$. Wie bereits erwähnt, sind dies die längsten Zellen dieser Art, die ich im Eichenholze finden konnte. -

Der Splint ist braungelb und das Keruholz dunkelrothbraun. Das Holz ist zähe, leicht zu schneiden, soll wenig dauerhaft sein und in Amerika nur als Brennmaterial dienen.

Vorkommen: Die "Water oak" ist ein kleiner Baum von $30-50^{\prime}$ Höhe, findet sich auf niedrigem Grunde an Teichen und Flüssen in Maryland, Arkansas, im südlichen Florida und östlichen Texas.

\section{Quercus nigra L.1.)}

"Black Jack oak". „Barren oak". Syn.: Q. ferruginea Mrchx.

Q. quinqueloba Engelm.

Q. aquatica Loold. cat. 1836.

Q. aquatica v. quinqueloba Alph. DeC.

Die Jahrestinge durch 4 I agen breite Ringe grosser $0,22-40 \mathrm{~mm}$ weiter Gefüsse begrenzt. Letztere enthalten Thyllen. Die kleinen Gefïsse sind $0,15 \mathrm{~mm}$ weit, setzen radiale, auf dem Stammquerschnitt baumartig angeordnete breite Gruppen zusammen. Jedoch kommen dieselben auch wie bei den vorigen Arten in einfachen breiten Zügen vor. Die Stumpfzellen stehen in matthellen Reihen den Kreisen grosser Gefüsse parallel in deutlich tangentialer Anordnung. Mit dem Mikroskop betrachtet erscheinen sie in engeren und weiteren Maschen unı kürzeren Reihen. Der Radialschnitt ist regelmässig gestreift, obgleich weniger deutlich als bei $Q$. falcata. Die Markstrahlen sind $0,75 \mathrm{~mm}$ breit, $6-8 \mathrm{~mm}$ hoch, haben einen tangentialen Abstand von $2,5 \mathrm{~mm}$ (im Mitfel) und sind auf $15 \mathrm{qmm} \mathrm{d.T.}$ zu 14 vertheilt. - Der Spiegel ist gross und rothbraun. Der Splint ist gelblichroth, das Kernholz bramroth und schwer.

Technischer IV erth: Gering; das Holz wird als Brennmaterial geschätzt. Dem Wasser ausgesetzt fault es leicht.

Vorkommen: Ein kleiner Baum, der kaum 25' hoch werden soll, wächst auf kiesigem oder sandigem Boden auf Long-Island, in

1) Sargent'sche Sammlung No. 229 , 
New-Tork, im siidlichen Florida, Nebraska, Indian-Territory und im östlichen T'exas.

y) In den concentrisehen Ringen grosser Gufisse im Frühlingsholz lassen sich in radialer Richtung gestreckte Gruppen mit blossem Auge deutlich untesscheilen. Die Jahresringe sind stark entwickelt. In ihnen betinden sich schmale, meist einschichtige radiale Reihen kleiner 0,05-0,20 $\mathrm{mm}$ weiter Gefïsse, von denen die engsten im Herbstholze liegen. Die tangentialen Reihen der Stumpfzellen siod locker, erscheinen breit auseinander gezogen und werien häufig von Holzspitzzellen durchsetzt. Die breiten Markstrahlen sind horizontal $1,8 \mathrm{~mm}$ (im Mittel) von einander abstehend. Ihre Breite ist jedoch in dell einzelnen Eichenarten verschieden.

\section{Quercus Cerris L.")}

"Zerr- oder Burgundereiche". Syn.: Q. austriaca Willd.

Q. Aegilops Scop.

Q. Aesculus L. mant.

Q. crinita Lam. dict.

Q. frondosa Mill.

Die grossen Gefäisse sind seitlich zusammengedrückt. Sie messen in ratialer Richtung $0,25-0,30 \mathrm{~mm}$, in tangentialer $0,15-0,21 \mathrm{~mm}$. Die kleinen Gefässe sind sehr vereinzelt, lassen aber dennoch eine deutliche radiale Anordnung erkennen. Die breiten Reihen der Stumpfzellen stelien genau parallel mit den Grenzzellen des Herbstholzes und zeigen auf dem Querschnitt genau dieselben convexen Bogen wie diese. Unter dem Mikroskop erscheinen ilne Reihen auf dem Qnerschnitt maschig verzogen, zuweilen sind auch kleinere Gruppen bemerkbar. Hier wie in allen anderen Eichen sind sie sogleich an ihrem weiteren Lumen und ihren diinneren Wäinden kenntlich. Der Radialschnitt ist nicht regelmässig streifig, falls die Stumpfaellen nicht in scharfbegrenzten dichten Reihen stehen. In einem jüngeren Stamme aus dem königl. berliner botanischen Garten waren dieselben in schmalen tangentialen Reihen parallel den platten Grenzzellen des Herbstholzes in den dïnnen Jahresringen regelmässig

1) ex horto regimont. et berol. 
in der Anzahl von 5-8 vorhanden. Hier war auch der Radialsehnitt sehr deutlich regelmässig gestreift.

Die breiten Markstrahlen stehen horizontal 2-2,5 $\mathrm{mm}$ ab, sind $1-1,5 \mathrm{~mm}$ breit, $10-12 \mathrm{~mm}$ hoch. Auf $15 \mathrm{qmm}$ d. T. kommen ihrer 20-30. Besonders bei dieser Eiche fällt die rothbraune Färbung der Markstrahlzellen in der Gegend des Herbstholzes der einzelnen Jahresringe auf. Die mittleren Zellen der Strahlen erscheinen wic zurïckgezogen, oder eingesenkt, eine Eigenthümlichkeit, die auch ganz besonders deutlich bei Q. laurifolia, glabra und sehr vielen anderen Eichen hervortritt. Die Markstrahlzellen in der Mitte des Strahls sind meist kürzer und dickwandiger als die übrigen. Dass sie sehr zahlreich geport sind, habe ich bereits an anderen Orten erwähnt. Der Splint ist gelblich weiss, das Kernholz rothbraun. Die Spiegel sind breit, braun und zahlreich. - Das Holz der Q. austriaca Willd. zeigt denselben anatomischen Bau und Alph. De Candolle zieht daher wohl mit Recht ${ }^{1}$ ) dieselbe zu der beschriebenen Art. Das Holz der (2. Cerris ist schwer und zähe. Es wird zu den mannigfachsten Geräthschaften verarbeitet. Nur zu Flüssigkeitsbehältern und Schiffen wird es nicht verwendet, wie bereits Wi iesner ${ }^{2}$ ) betont.

Vorkommen: Im südlichen Europa; findet sich aber auch noch in Mähren (Pohlauer Berge) ${ }^{3}$ ).

35. Quercus serrata 'Thunb. ${ }^{4}$ )

Syn.: Q. acutissima Carr.

Q. polyantha Lindl.

Die grossen Gefïsse sind 0,35-0,40 mm weit, enthalten Thyllen. Die kleinen Gefïsse sind im Herbstholz sogar nur $0,14 \mathrm{~mm}$ weit. Ihre radialen Reihen sind sehr sehmal, zeichnen sich aber durch grössere Helligkeit aus. Auf dem Querschnitt erscheinen sie zulweilen baumartig angeordnet. Neben längeren befinden sich auch kürzere, nicht durch die ganze Breite des Jahresringes verbreitete,

1) Alph. DeCandolle: Prodromus, Fasc. II. p. 4\%.

2) Rohstoffe, p. 604.

3) Kotschy: Die Eichen Europas und des Orients.

4) ex museo petrop. 
radiale Gruppen. Die Stumpfzellen erscheinen in lockeren, auf dem Querschnitt maschigen, tangentialen Reihen, verursachen aber dennoch eine dentliche Längsstreifung der radialen Schnittfläche. Die grossen $0,75 \mathrm{~mm}$ breiten braunen Narkstrahlen sind 5-10 $\mathrm{mm}$ hoch und tangential 1-2 $\mathrm{mm}$ abstehend. Auf $15 \mathrm{qmm} \mathrm{d.} \mathrm{T.} \mathrm{kommen} \mathrm{ihrer}$ etwa 20. Die Spiegel sind braun und das feste Holz tief rothbraun.

Vorkommen: Das untersuchte Stammstück wurde von Maximowicz auf Nippon gesammelt und dem petersburger Nuseum einverleibt. Aus diesem gelangte es an den hiesigen Königl. botanischen Garten. - Q. serrata soll nach Brandis ') ein mittelgrosser hinfälliger Baum sein. (Das untersuchte Stiick aus dem petersburger Museum war auch bereits schadhaft.)

36. Quercus Phellos L. ${ }^{2}$ )

"Willow oak". Syn.: Q. virginiaua Pluck.

Die grossen Gcfässe erscheinen seitlich etwas zusammengedrückt. Ihr radialer Durchmesser ist $0,25-0,39 \mathrm{~mm}$, der tangentiale dagegen nur $0,23-0,29 \mathrm{~mm}$. Die kleinen Gefässe sind im mittleren Theil des Jahresringes $0,10 \mathrm{~mm}$ weit und deutlich sichtbar, im Herbstholz sind sie dagegen nur $0,14 \mathrm{~mm}$ weit und daher nicht mit blossem Auge wahrzunehmen. Die radialen Reihen sind einfach und gleichmässig. Nicht selten finden sich kürzere, nicht durch die $9 \mathrm{~mm}$ breiten Jahresringe verbreitete Züge kleiner Gefässe.

Zwischen je 2 breiten Markstrahlen befinden sich 2-3 solcher radialer Gefässgruppen. Die Stumpfzellen sind nicht in dichten tangentialen Reilien, sondern vereinzelt und in kürzeren tangentialen Gruppen anzutreffen. Doch lassen sie, im Ganzen betrachtet, eine tangentiale Anordnung erkennen. Dem blossen Auge erscheinen sie auf Querschnitten als matte breite Streifen ohne bestimmte Umrisse. Ebenso undentlich ist auch die Streifung des Radialschnitts. Die breiten Markstrahlen ${ }^{3}$ ) sind horizontal $1-1,5 \mathrm{~mm}$

1) 1. c. p. 486 .

2) Sargent'sche Sammlung No. 232. Taf. Xul Fig. 28 vgl. Figurenerklärung.

3) Bei dieser und der folgenden Art rerbreitern sich die breiten Markstrahlen im Frühlingsholz um ein Weniges. 
entfernt, $0,3 \mathrm{~mm}$ breit, $5-20 \mathrm{~mm}$ hoch und auf $15 \mathrm{qmm}$ d. 'T. zu 20 - 30 angeordnet. Die Spiegel sind rothbraun wie das Kernholz. Der Splint ist hellröthlich. Die Holzspitzzellen sind $0,02187 \mathrm{~mm}$ (im Mittel) breit, besitzen ein Lumen von nahezu $0,012 \mathrm{~mm}$.

Technischer Werth: Nach Sargent ist das Holz von geringer Bedeutung; es wird zuweilen zu Felgen verarbeitet. Es ist zühe, aber von wenig Dauerhaftigkeit.

Vorkommen: Dieser mittelgrosse Baum soll sich gewöhnlich an sumpfigen Ufern und an Gestaden von Long-Island, Florida, vou Kentucky bis zum östlichen Texas verbrciten.

\section{Quercus coceinea Wang. ${ }^{1}$ )}

"Scarlet oak".

Ganz äbnlich wie die vorige im anatomischen Bau. Nur sind die radialen Reihen der kleinen Gefässe noch schmaler, die tangentialen Reihen der Stumpfzellen dichter und die Lä̈ngsstreifen auf dem Radialschnitt deutlicher. Die grossen Markstrahlen sind auf dem Stammquerschnitt gelblichroth, besitzen 11 ur $0,28 \mathrm{~mm}$ Breite und den tangentialen Abstand von 1-1,5 mm. Auf $15 \mathrm{qmm}$ d. T. kommen etwa 30 Markstrahlen, die nur 2-12 $\mathrm{mm}$ hoch sind. Die Spiegel sind gelbröthlich wie der Splint. Das Kernholz ist rothbraun, aber heller als bei voriger Art. Das Holz ist zähe, jedoch leicht zu schneiden.

Vorkommen: Auf leichtem sandigen Boden in der Nähe der Küste in östlichen Massachusetts und Minnesota.

b) Mit dickwandigen Gefässen einerlei Art, welche im Mittel $0,16 \mathrm{~mm}$ weit sind. Ihre Reihen zeigen im Ganzen radiale Anordnung. Jahresringe makroskopisch undeutlich begrenzt.

a) Die radial angeordueten Reihen der Ciefässe sind meist breit.

1) Nach Sargent "Catalogue" etc. p. 47 wirl diese Eiche mit Q. tincturia verwechselt. Nach den anatomischen Jerkmalen lassen sich beide Arten auseinanderbalten. Sargent'sche Sammlung No. 213. 
38. Quercus virens Ait. ${ }^{1}$ )

"Life oak". Syn.:"Q. sempervirens Ait.

Q. oleoides Cham. et Schl.

Q. retusa Liebm.

Die Gefässe sind im Mittel $0.20 \mathrm{~mm}$ weit. Ihre Reihen sind ungleich breit und in der Anordnung zuweilen auf dem Querschnitt haumartig. Die radialen Züge derselben vereinigen sich zuweilen auch tangential. Im Friihjahrsholz des Splints sind die Gefïsse um ein Weniges weiter, doch nicht mit der Regelmässigkeit wic bei der Gruppe a. Es kommen auch radiale, völlig isolirte Gruppen von Gefïssen ror. Dic tangentiale Anordnung der Stumpfzellen ist zwar vorhanden, aber nur undeutlich zu bemerken. Luter dem Mikroskop zcigt der Querschnitt, dass die Stumpfzellen in kür\%cren tangentialen Gruppen und maschenartig zwischen den dickwandigen Holzspitzzellen stehen. Nur in schmalen Jahresringen sind ihre Reihen dichter. Dic grussen Markstrahlen ${ }^{2}$ ) sind $0,5-1 \mathrm{~mm}$ breit, horizontal $1-3 \mathrm{~mm}$ entfernt und 5-10 mm hoch. Auf 15 q $\mathrm{mm}$ d. 'T. stehen 10 Markstrahlen. - Der sfriegel ist gelblich. Der Sullint ist gelblichroth, diss Kernholz dagegen gelbbraun.

Technischer Werth: Das feste schwere IIolz findet eine allgemeine Verwendung, wird anch zu Schiff bauten benutzt.

Vorko mmen: An den Gestaden Floridas, am Golf von Mexiko, Texas, Tirginien.

39. (Quercus oblongifolia Torr. ${ }^{3}$ ) "Evergreen white oak". „Life oak".

Gefässe wie bei voriger Art. Die tangentialen Reihen der Stumpfzellen sind fast ganz undertlich; doch zeigen sie besonders in Frühlingsholz eine dichtere Anorthung. Die Grenze der Jahresringe wird an Holzspitzzellen, die tangential verbreitert sind, erst unter dem Mikroskiop zum Theil erkannt. Die grossen Markstrahlen sind $0,5-1 \mathrm{~mm}$ breit, $3-8 \mathrm{~mm}$ hoch und stehen horizontal $2-2,5 \mathrm{~mm}$ ab. Auf $15 \mathrm{qmm}$ d. 'T. kommen 15-20 Markstrahlen. Einige von

1) Sargent'sche Sammlung No. 238.

2) Einige scheinen die Peripherie des Stammes nicht zu erreichen.

3) Sargent'sche Sammlung Nr. 230. 
ihnen zeigen die Eigenthümlichkeit, noch vor Erreichung der Peripherie sich aufzulösen („aussetzende Strahlen" Th. Hartig's). Im Frühlingsholz verbreitern sich alle grossen Markistrahlen. Thre Farbe ist auf dem Stammquerschnitt gelblichgrau und ein älnnliches Aussehen besitzen auch die breiten Spiegel. Das schwere, harte, aber leicht hrechbare Holz ist grau mit einem bräunlichen Anflug. Jahresringe concav.

Vorkommen: Auf den Gebirgen des südwestlichen Californiens von San Diego bis Los Angelos und in Chihualıa.

Eine schöne Eiche, deren Stamm 2-21/2' im Durchmesser breit ist.

40. Quereus chrysolepis Liebm. ${ }^{1}$ )

„California Life oak". Syn.: Q. fulvescens Kell.

Q. crassipocula Torr.

Gefïsse sind sehr eng, kaum 0,09 mm weit; sie sind in radialen isolirten Gruppen wie auch in tangential zusammenhängenden Zügen zu bemerken. Jahresringe sehr undentlich, sind aber dennoch theilwcise durch platte Holzspitzzellen angedeutet, die man nur mit dem Mikroskop erkemen kann. Die Stumpfzellen zeigen eine ähnliche Anordnung wie bei voriger Art. Die grossen Markstrahlen sind horizontal $3-8 \mathrm{~mm}$ von einander entfernt, ihre Breite beträgt 0,5-0,75, die Höhe 2-16 mm. Auf 15 qmm d. T. finden sich 8-16 breite Markstrahlen. Holz und Markstrahlen sind braunroth. Auch hier zeigen die Markstrahlen die bei voriger Art erwähnte Eigenthïmlichkeit, vor der Peripherie auszusetzen.

Vorkommen: In Californien an der Küste und an den westlichen Abhängen der Sierra Nevada.

\section{Quercus rugosa Née. $\left.{ }^{2}\right)$}

Gefässe wie bei voriger Art angeordnet und von nahezu gleicher Weite. Die radialen Gruppen derselben verschmelzen sehr oft tangential. Jie Stumpfzellen stehen theils in deutlichen concentrischen Kreisen, theils bilden sie nur kürzere oder längere tangentiale Reihen.

1) ex museo petrop.

2) ex horto berol. 
Die breiten Harkstrahlen sind häufig getheilt, enthalten Gruppen von Holzspitzzellen und Gefässen zwischen ihren Zellen. Die meisten dieser Strahlen sind secundär, doch waren auch primäre zu bemerken. Ihre Breite ist nicht selten $1 \mathrm{~mm}$, Höhe $8 \mathrm{~mm}$ und auf $15 \mathrm{qmm}$ d. T. stehen 11 breite Markstrahlen. Die schmalen Markstrahlen sind als feine hellere Streifen zwischen den ersteren zu bemerken. Das Holz in der Richtung der Markstrahlen leicht spalthar, ist rothbraun und lässt sich leicht schneiden.

Vorkommen: In Mexiko.

Q. rugosa ist ein Baum von mittlerer Grösse.

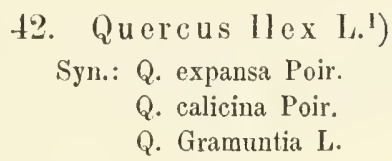

Der untersuchte Stamm war noch jung und hatte einen Durchmesser von $1,4 \mathrm{~cm}$. Die Gefässe sind in breiten radialen Reihen angeordnet, lommen tangential selten in Berührung. Die Markstrahlen sind wie bei voriger Eiche von Holspitzzellen stark durchsetzt, meist seeundär, doch konnte ich auch primäre Narkstrahlen entdecken, welche im Nark mit 4 und mehr Zellen Breite ${ }^{2}$ ) ihren Ursprung nahmen und sich nach der Peripherie des Stammes hin verbreiterten. Zwischen je 2 Markstrahlen befindet sich ein breiter radialer Zug gleichgrosser Grefïsse. Die Stumpfzellen stehen in kürzeren und längeren tangentialen Reihen, namentlich in jüngeren Jabresringen. In älteren sind ihre Reihen durch Holzspitzzellen und Gefässe gelockert. Das Kernholz ist röthlich, der Splint gelblichweiss und zähe.

Vorkommen: In Siid-Europa; erreicht nach Kotschy ${ }^{3}$ ) ihre Nordgrenze am Nordufer des Garda-Sees bei Riva und Duino bei Triest. Im südlichen Frankreich ist es nach genanntem Autor das gemeinste und geschätzteste Brennholz.

Die Varietät Q. Fordii Hort. lietet in anatomischer Hinsicht nichts Abweichencles dar.

1) ex horto berolinense. Einen gleichen Bau zeigte auch ein $7,5 \mathrm{~mm}$ starker Stamm von Q. Turneri Willd.

2) horizontal.

3) 1. c. No. 38 . 


\section{Quercus coceifera L. ${ }^{1}$ )}

Syn.: Q. graeca Kotschy.

Wie Q. Hlex. Stamm $1 \mathrm{~cm}$ Durchmesser.

44. Quereus Calliprinos L.

Wie Q. Ilx. Stamm $3 \mathrm{~mm}$ Durchmesser.

45. Quereus lanuginosia Don.

SyH.: Q. Banga Ham.

Q. lanata Waill.

Der junge Stamm mass 1,1 cm im Durchmesser. Ciefüsse und Stumpfzellen wie bei Q. Ilex angeordnet. Die breiten Markstrahlen sind spärlich. Das zähe Holz ist röthlich mit gelblichem Anflug.

Vorkommon: In Neapel, wo sie als ein grosser Baum sich vurfindet. -

Alle diese jungen Eichenstïmme waren mit nur 0,07 mm (im Mittel) weiten und $0,2 \pm \mathrm{mm}$ langen Gefüssen verschen. Die $1101 \%$ spitzzellen zeigten eine länge von nur $0,6 \mathrm{~mm}$ im Mittel. Bei Q. Calliprinos, einem allerdings schr jungen Stamm, waren sie nur $0,3 \mathrm{~mm}$ lang.

46. Quercus paucilammellosa Hook. ${ }^{2}$ )

Syn.: Q. lammellosa Hook.

Die Jahresringe sind sehr undeutlich, selbst durch das Mikroskop erkennt man ihre Gronzen nicht immer, weil die Holzspitzzellen der äussersten Jahreslagen nur streckenweise tangential verbreitert vorkummen. Die Stumpfzellen sind in den einzelnen tangentialen Reihen locker eingeordnet, crscheinen auf dem Querschnitt maschig vertheilt und gänzlich isolint, aber selbst in dieser unregelmässigen Anordnung ist eine tangentiale Richtung nicht zu verkennen. Die liefäse sind in einigen Lagen dieses Eichenholzes etwas weiter als sie sonst in den Eichen dieser Gruppe angetroffen werden. Ich fand ihren Durchmesser $0,23 \mathrm{~mm}$. In vielen anderen Lagen waren sie

1) No. $43-45$ ex hort. herol.

2) ex museo petrop. 
im Mittel $0,16 \mathrm{~mm}$ weit. Viele ron ibnen sind sehr dicht mit Thyllen erfiillt, so dass sie auf dem Querschnitt als weissgraue Punkte erscheinen. Die grossen Markstrahlen sind $1-1,5 \mathrm{~mm}$ breit, haben einen horizontalen Abstand von $2 \mathrm{~mm}$ bei einer Höhe von $5-18 \mathrm{~mm}$. Auf $15 \mathrm{qmm} \mathrm{d}$. T. fand ich ihrer $12-15$. Auf dem Querschnitt des Stamınes zeigen sie seitlich ron der Mediane viele spitze Zellen; nicht selten sind sie ron Holzspitzzellen quer durchsetzt. Hin und wieder gehen auch Gefïsse durch sie hindurch. 1)ie meisten breiten Markstrahlen erstrecken sich bis zur Rinde, doch liessen sich auch einige nicht bis zur Peripherie reichende Strahlen vorfinden. Einige Spitzzellen in der Nähe der Markstrahlen führten deutlich nachweisbaren Gerbstoff. Sie erreichen nicht selten die Länge von $1,6 \mathrm{~mm}$ und eine Breite von $0,02 \mathrm{~mm}$. Sowohl Markstrablen als auch Stumpfzellen enthalten braunen Gerbstoff. - Das Holz ist dunkelbraunroth und hart.

Torkommen: In Sikkin.

Nach Brandis's) soll diese Eiche $40-60^{\prime}$ hohe Stämme mit 9-15' Umfung haben.

\section{Quercus glabra Thunbg. ${ }^{2}$ )}

Die Jahresringe sind deutlich durch breite dunklere Holzspitzzellen begrenzt. Die Grefïsse sind in radialen Gruppen angeordnet, haben nur die Weite von $0,16 \mathrm{~mm}$ im Mittel. Im Frühlingsholz sind die Gruppen breiter, im Herbstholz meist schmaler. Die Stumpfzellen sind in tangentialen schlängelnden Reihen angeordnet, welche einen regelmässigen radialen Abstand haben, was man am deutlichsten auf dem regelmässig längsstreifigen radialen Schnitt erkennen kann. Die grossen Markstrahlen sind tangential $1-3 \mathrm{~mm}$ von einander entfernt, $0,5-1 \mathrm{~mm}$ breit und $3-10 \mathrm{~mm}$ hoch. Auf $15 \mathrm{qmm}$ d. T. zählılte ich 20 Narkstrahlen. Sie werden von Holzspitzzellen nicht selten durchsetzt und verlalten sich wie in $\mathrm{Hol}_{2}$ der vorigen Eiche. Die Holzspitzzellen eines jungen Stammes waren $0,6 \mathrm{~mm}$, die des alten $1,01 \mathrm{~mm}$ lang. Die Breite blieb bei beiden

1) 1. c. p. 488.

2) ex hort berol. et petrop. 
$0.017 \mathrm{~mm}$ im Mittel. Das Holz des ersteren ist hellrothbraun, des letzteren tief braunroth (chocoladefarben).

Vorkommen: Auf Kia-Siu.

48. Quercus Burgeri Bl. ${ }^{\text {) }}$

Syn.: Q. gemelliflora Burger.

Anorduung der Gefüsse und Stumpfzellen wie bei voriger Art. Die hellen breiten Markstrahlen stehen tangential $2-5 \mathrm{~mm}$ ab, sind 0,25-0,4 breit, $2-9 \mathrm{~mm}$ hoch. Auf $15 \mathrm{qmm}$ d. T. waren etwa 14 breite Markstrahlen zu zählen. Das Holz ist hellröthlich.

Vorkommen: Auf Nippon von Maximowicz gesammelt.

\section{Quercus gilva Bl. ${ }^{2}$ )}

Gefässe in etwas schmaleren radial angeordneten Reihen, die aber tangential nicht selten zur Verschmelzung kommen. Auch isolirte radiale Gruppen sind auf dem Quersehnitt zu bemerken. Die Stumpfzellen stehen in den radial getrennten, tangential verlaufenden Reihen weniger dicht als bei den vorigen Arten; in Folge dessen ist die Längsstreifung des radialen Schnitts weniger deutlich ausgeprägt. Die gelblichen breiten Markstrahlen zeigen dieselben Grössen- und Anordnungsverhältnisse wie bei voriger Eichenart. Das $\mathrm{Holz}$ ist röthlichgelb.

Vorkommen: Auf Kiu-Sin bei Nagasaki ron Maximowicz gesammelt.

50. Quercus thalassica Hance. ${ }^{3}$ )

Syn.: Q. inversa Lindl. -

Q. acuta Sieb.

Q. sieboldiana Bl.

Jahresringe werlen durch die Holzspitzzellen des Herbstholzes angedeutet. Die Gefïsse stehen theils in breiteren, theils in schmalcren einreihigen schlängehnden radialen Zügen. Auch völlig isolirte

1) ex museo petrop.

2) ex museo petrop.

3) ex museo petrop. 
Gruppen sind zu bemerken. Die Stumpfzellen stehen in deutlich abgesonderten concentrischen Kreisen und verursachen die regelmässige Längsstreifung des Radialschnitts. Die Markstrahlen verhalten sich wie bei voriger Art, haben jedoch eine mehr braune Farbe. Das Holz ist an gesunden Stellen rothbraun (von Chocoladefarbe), fest und dicht.

Vorkommen: Im nördlichen China und Japan. Das untersuchte Stammstück rührt von einem von Maximowicz bei Nagasaki entdeckten Baum her.

$\beta$ ) Die radialen Gruppen der Gefïsse sind schmal, 1-2schichtig, werden tangential selten vereinigt angetroffen.

\section{Quercus Suber L. ${ }^{1}$ ) „Korkeiche“.}

Jahresringe meist sehr unregelmässig gebildet, von breiten Holzspitzzellen begrenzt. Nicht selten sind im Frühlingsholz etwas weitere Gefässe, welche 0,20-0,23 $\mathrm{mm}$ im Durchmesser haben, zu bemerken, doch bringen sie im Allgemeinen durch ihre Anordnung den Charakter dieser Gruppe zum Ausdruck. Ganz besonders gilt dieses vom Kernholz. In den äussersten Jahresringen kommen die radialen Reihen auch tangential näher zu stehen. Die Holzstumpfzellen stehen in concentrischen Kreisen, tangentialen Binden und vereinzelten Gruppen. Die hellrothen Markstrahlen sind $0,8 \mathrm{~mm}$ (im Mittel) breit, stehen sehr dicht $(1-1,5 \mathrm{~mm})$ und sind $3-10 \mathrm{~mm}$ hoch. Auf $15 \mathrm{qmm}$ d. T. kommen ihrer etwa 20. Das hellrothbraune Holz ist fest und zïhe. ${ }^{2}$ )

Vorkommen: In Spanien, in der Berberei, Süd-Frankreich, Italien, Dalmatien und Griechenland. Der nördlichste Punkt ihrer Verbreitung ist nach $\mathrm{Kotsch}^{3}$ ) Istrien, wo sie bei Pola einen Bestand bilden soll.

1)ie Korkeiche besitzt 30-50' Höhe und 2' im Durchmesser.

1) ex hort. berol.

2) Von dieser Eiche wird das Holz wenig geschützt, nur der Kork wird von ihren Stämmen gewonuen.

3) 1 c. No, 33 . 


\section{Quercus agrifolia Née. $\left.{ }^{1}\right)$ \\ „Enceno".}

Auch hier sind die Gefässe im Frühlingsholz ein klein wenig grösser, ganz wie bei Q. Suber. Sie sind in 1-2schichtigen Reihen radial angeordnet. Letztere weichen selten von der Richtung des Radius ab. Auch gänzlich isolirte Gefüsse kommen unter den dickwandigen Spitzzellen vor. Die Holzstumpfzellen stehen in deutlichen etwas maschigen tangentialen Reihen, die zuweilen auch eine schlängelnde Anordnung zeigen. Besonders an Stamm dieser Eiche bemerkt man auf dem radialen Schnitt 2 Systeme sich krenzender paralleler Streifen. Die radialen Streifen rühren von den kleinen Markstrahlen her und die regelmässigen Längsstreifen werden von den Reihen der Stumpfzellen verursacht. Die $0,25-0,50 \mathrm{~mm}$ breiten grossen Markstrahlen sind tangential nur $2-4 \mathrm{~mm}$ entfernt, $5-6 \mathrm{~mm}$ hoch, werden häufig ron Holzspitzzellen quer durehsetzt und stehen zu 15 auf 15 gmm. Der Spiegel ist tief braunroth. Das Holz besitzt eine liellbraunrothe Farbe. Es scheint leicht und ron geringer Festigkeit zu seiv.

Vorkommen: An der californischen Küste, südlich von San Franciseo bis Mendocino County. -

Ein 120' holer Baum, dessen Stamm 8-21' im Imfang messen kann. Soll auch strauchartig vorkommen. Untersucht wurde das Holz des Baumstammes. -

\section{Quereus glauca Thunbg. ${ }^{2}$ )}

(Sectio Cyclobalanus.)

Die Jahresringe werden durch dickwandigere dunklere Holzspitzzellen regelmässig begrenzt. Die Gefässe stehen in einfachen, meist einschichtigen radialen schlängelnden Reihen. Auf dem Querschnitt zeigen sie nur selten tangentiale Annähcrung, gewähren aber öfter in ihrer Anordnung ein baumartiges Aussehen. Auch sehr kurze radiale Gruppen von 2-4 Gefässen sind zu bemerken. Die Stumpfzellen stehen in diehten regelmässigen concentrischen hreisen. Bei

1) ex museo petrop.

2) ex museo petrop. 
keiner der von mir untersuchten Eichen zeigt der Radialschnitt eine so dentliche gleichmässige Längsstreifung. Die röthlichen grossen Markstrahlen sind etwa $0,3-0,4 \mathrm{~mm}$ breit, stehen von einander tangential etwa $3 \mathrm{~mm}$ als, sind $5-10 \mathrm{~mm}$ hoch und waren auf 15 ymm d. T. zu 13 vertheilt. Das tiefbraunrothe Holz ist hart. Das Lumen der Spitzzellen klein.

Vorkommen: In Japan.

Die folgende Art findet ihren Platz am besten hier. Der spärlichen grossen Markstrahlen halber möchte ich sicht noch eine neve Gruppe bilden.

\section{Quercus cuspidata Thunbg.') (Sectio Chlamydobalanus.)}

Die Jahresringe werden von breiten Holzspitzzellen des Herbstliolzes begrenzt und durch $0,20 \mathrm{~mm}$ weite Gefässe angedeutet. Letztere stehen in schmalen einschichtigen Reihen im Frühlingsholz, wo auch die Holzspitzzellen etwas weitlichtiger sind. Die radialen Reihen der Gefässe zeigen auf dem Querschnitt meist eine baumartige Anordnung. Nicht selten bemerkt man ihre Reihen in einer zum Radius schiefen Richtung stehen. Im Herbstholz sind die engsten (iefüsse, die im Mittel nur $0,07 \mathrm{~mm}$ Weite haben. Die Länge derselben war im Nittel $0,50 \mathrm{~mm}$. Zuweilen zeigten ihre Enden eine leiterförmige Durchbrechung. Die $\mathbb{W}$ ände waren 0,0041-0,006 mm dick und zeigten grosse Hofporen (0,0)87-0,009 mm im Durchmesser). In dïnneren Jahresringen waren tangential weit ron einander abstehende zweischichtige Reihen enger Gefüsse wie gewölmlich radial angeordnet zu bemerken. Die Stumpfzellen sind zu contcentrisehen Kreisen im Stamm angeordnet. Die Flächen der radialen Schnitte sind regelmässig längsstreifig. Die breiten Markstrahlen sincl sehr spärlich, etwa $0,3-0,4 \mathrm{~mm}$ breit, $5-7 \mathrm{~mm}$ hoch, stehen tangential etwa $15 \mathrm{~mm}$ ab. ${ }^{2}$ ) Der spiegel ist undentlich uml seiu häufiges Fehlen auf dem radialen Schnitt verleiht diesem Eichenholz

1) Der untersuchte Stamm hatte einen Durchmesser von ca. $8 \mathrm{~cm}$, war vüliig morsch, so dass das IIolz sich mit dem Nagel eindrücken liess. (Ex museo petrop.)

2) Zuweilen auf Querschnitten gänzlich fehlend. 
ein fast birkenholzartiges Aussehen ${ }^{1}$ ). Auch die Holzspitzzellen lassen auf Querschnitten eine deutliche radiale Richtung in der Anordnung erkennen. Bei ler Lä̈nge von $1 \mathrm{~mm}$ (im Mittel) sind sie $0,020 \mathrm{~mm}$ breit und besitzen bei $0,0040 \mathrm{~mm}$ dicken Wänden ein Lumen von $0,0120 \mathrm{~mm}$. Das Holz ist auf dem Radialschnitt gelblich, auf dem Querschnitt gelblichbraun.

Vorkommen: Auf Kiu-Siu.

B. Breite Markstrahlen durch dazwischen tretende Holzbestandtheile in schmale, gruppig beisammenstehende Strahlen aufgelöst. Alles Uebrige wie in voriger Abtheilung der Gruppe $\beta$.

\section{Quercus dilatata Lindl. ${ }^{2}$ )}

Syn.: Q. floribunda Lindl. in Wall.

Jahresringe sind sehr unregelmässig und nur theilweise von breiten Holzspitzzellen begrenzt. Die Gefässe stehen in dem sehr dichten Holz in radialen Gruppen, die tangential isolirt sind. Die einzelnen Gefässe sind nur im Splint mit blossem Auge deutlich wahrnehmbar. Sie besitzen hier eine Weite von $0,18 \mathrm{~mm}$. Die tangentialeu Reihen der Stumpfzellen sind sehr locker und erscheinen auf dem Querschnitt maschig und in Gruppen angeordnet. Auch einzelne kürzere tangentiale Reihen sind anzutreffen. Die Markstrahlgruppen sind tangential 1-2 $\mathrm{mm}$ entfernt und haben eine Breite von 0,75 bis $1 \mathrm{~mm}$. Die Holzspitzzellen sind $1,7 \mathrm{~mm}$ lang, $0,017 \mathrm{~mm}$ breit, besitzen ein sehr enges Lumen, führen aber in der Nähe der Narkstrahlen Gerbstoff. Das rothbraune Holz ist sehr dicht und hart. Es hat das Aussehen des Mahagoniholzes.

Technischer Werth: Das harte Holz ist nach Brandis ${ }^{3}$ ) sehr dauerhaft, wird zu Bauten und Herstellung von Ackergeräth-

1) Es erinnert durch seinen Bau an Castanopsis indica Alph. DeC., der aber die breiten Markstrahlen fehlen. Auch sind die Gefässe weiter und wie bei Quercus glauca angeordnet.

2) ex museo petrop. Taf. XII, Fig. 29 Querschnitt.

Anm.: Das untersuchte Stück entstament dem Nuseum petropolitanuw, woher es mit der Auszeichnung „India (Simla, Punjab)“ an den hiesigen königl. botan. Garten gelangte. Das Holz ist an der Peripherie zwischen je 2 Jarkstrahlgruppen eingesenkt. - Vgl. anf Taf. XII, Fig. 27, bei Q. alba dasselbe.

3) l. c. p. 483. 
schaften benutzt. Am Satledsch (Sutlej) soll es höher geschätzt werden als das Holz aller anderen Eichen.

Torkommen: Q. dilatata ist ein grosser Baum des westlichen Himalaya.

\section{Kurze Uebersicht über die Gruppirung der Eichen nach anatomischen Gesichtspunkten.}

Hauptabtheilung A: Mit breiten grossen Markstrahlen.

Abtheilung a: Jahresringe durch concentrische Kreise grosser Gefüsse des Frühlingsholzes deutlich begrenzt, schon mit blossem Auge wahrnehmbar. Kleinere Gefässe befinden sich zu radialen Reihen im Herlsstholz angeordnet.

I. Unterabtheilung: Mit dünnwandigen Gefässen.

Gruppe $\alpha$ : Die radialen Reihen kleiner enger Gefässe stossen tangential aneinander.

† Die rarlialen Reihen vereinigen sich im Herbstholz vorwiegend.

1. Quercus lyrata Walt. (Leucobalanus Eng., Lepidobalanus DeC., sectio I. Eulepidobalanus Orst.).

t† Die radialen Reihen vereinigen sich im Herbstholz tangential zum Theil.

2. Q. a]ba L. (Lepidobalanus DeC., Teucobalanus Eng., sect. I. Eulepidobalanus Ørst.).

3. Q. Durandii Buck. (Lencobalanus Eng., Jepidobalanus DeC.).

4. Q. stellata Wang. (Leucobalanus Eng., Lepidobalanus DeC.).

5. Q. macrocarpa IIchx. (Leucobalanus Eng, Lepidobalanus DeC., sectio I. Eulepidobalanus Orst.).

6. Q. Wislizeni Alph. DeC. (Melanobalanus Eng., Lepidobalanus DeC., subg. III. Erythrobalanus, sect. II. Nicrocarpaea Orst.)

7. Q. Prinus L. (Leucobalanus Eng., Lepidobalanus DeC., sect. II. Prinus Orst.).

8. Q. Garryana Dougl. (IRucohalanus Eng., Lepidobalanus DeC., sect. I. Eulepidobalanus Ørst.). 
9. Q. bicolor var. Michauxii Eng. (Leucobalanus Eng., Lepislobalanus De(. , sectio II. Prinus Orst.).

Gruppe $\beta$ : Die radialen Reihen kleiner Gefässe sind verhältnissmässig schmal und tangential vorwiegend isolirt.

10. Q. bicolor Willd. (Leucobalanus Eng., Lepidobalanus DeC., sectio II. Prinus Orst.)

11. Q. sessiliflora Sm. (Lepidobalanus DeC., sectio 1. Eulepidobalanus Orst.).

12. Q. iberica Stev. (Lepidobalanus DeC.)

13. Q. grosseserrata Bl. (Lepidobalanus DeC., sect. II. Prinus Orst.).

14. Q. castaneifolia C.A. Mey. (Subg. III. Cerris, sect. I. Eucerris Orst.).

15. Q. pedunculata Ehrh. (Lepidobalanus DeC., sectio I. Eulepidobalanus Orst.).

16. Q. Thomasii Ten. (Lepidobalanus DeC., sectio I. Eulepidobalanus Orst.).

17. Q. undulata vas. grisea Eng. (Leucobalanus Eng.).

18. Q. mongolica Fisch. (Lepidobalanus DeC, sectio IV, Ilex Orst.).

19. Q. macranthera Fisch. et Mey. (Tepidobalanus DeC.).

20. Q. heterophylla IIchx. (Lepiclobalanus).

Gruppe $\gamma$ : Die radialen Reihen kleiner Gefïsse sind sehr schmal und letatere etwas in der Weite verschieden. Die grossen Gefässe lassen in den concentrischen Ḱreisen Gruppen erkennen.

21. Q. lobata Née. (Lencobalanus Eng., Lepidobalanus DeC., sect. I. Eulepidobalanus Orst.).

22. Q. glandulifera Bl. (Lepidobalanus DeC.. sect. II. Prinus Orst.).

II. Unterabtheilung: Mit dickwandigen Gefüssen.

Gruppe $\alpha$ : Grosse Gefïsse in den concentrischen Kreisen undeutlich gruppirt. Kileine Gefässe eng in schmalen radialen Reihen.

23. Q. rubra nebst var. texana Buckl. (Nelanobalanus Eng., Sulgg. III. Erythrobalanus, sectio I. Euerythrobalanus Orst.).

24. Q. tinctoria Bartr. (Melanobalanus Eng., Erythrobalanus, sect. I. Euerythrobalanus Orst.).

Gruppe $\beta$ : Grosse Gefïsse wie in voriger Gruppe. Die radialen Züge kleiner Gefïsse breit; letztere iteit, meist mit blossem Auge wahrnehmbar. 
25. Q. imbricuria MIchx. (Nelanubalanus Eng., Erythrobalanus, sectio II. Milirukarpaea Orst.).

26. Q. hypoleuca Eng. (Melanobalanus Eng, Erythrobalanus, sect. II. Mikrokarpaea Orst.).

27. Q. laurifolia Mchx. (Mclanobalanus Eug.).

28. Q. Kielloggii Nowb. (Mclanobalanus Eng., Euerythrohalanus, sect. I. Euerythrobalanus Orst.).

29. Q. palustris Mchx. (Melanobalanus Eng., Erythrobalanus, sect. I. Euerythrobalanus Orst.).

30. Q. falcata Mclix. (Melanobalanus Eug., Erythrubalanus, sect. II. Euerythrubalanus Orst.).

31. Q. Catesbaei Mclux. (Melanubalanus Eng., Erythrobalanus, sect. 1. Euerythrobalanus Ørst.).

32. Q. aquatica Nutt. (Melanobalanus En!r., Erythrobalanus, sect.1I. Mikrokarpaea Orst.).

33. Q. nigra L. (Nelanobalanus Eny., Erythrubalanus, sectio II. Mikrokarpaea Orst.).

Gruppe $\gamma$ : Mit dentlich radialer Gruppirung in den Kreisen grosser Gefässe des Frühlingsholzes. Die radialen Reihen ḱleiner Gefässe schmal und gerade. Enge Gefässe mit blossem Auge sichtbar.

34. Q. Cerris L. (Subg. III. Cerris, sectio I. Eucerris Orst.).

35. Q. serrata Thunb. (Subg. III. Cerris, sect. II. Erythrobalanopsis Orst.).

36. Q. Phellos L. (Melanobalanus Eug., sulgg. III. Erythrobalanus, sectio II. Mikrokarpaea Orst.).

37. Q. coccinea Wang. (Melanobalanus Eng., subg. III. Erythrobalanus, sectio I. Euerytrhobalanus Orst.).

Abtheilung b: Mit dickwandigen Gefässen einerlei Art, welche zu radialen Reihen oder Gruppen geordnet sind. Jahresringe mit blossem Auge undeutlich zu erkennen, werden meist nur von dickwandigen Holzzellen der äussersten Schichten des Herbstholzes angedeutet. Mikroskopisch wahrnehmbar.

Gruppe $\alpha$ : Die radial angeordneten Reihen der Gefïsse sind meist breit. 
33. Q. virens Ait. (Leucobalanus Eng., Lepidobalanus DeC., sect. IV. Ilex Orst.).

39. Q. oblongifolia Torr. (Leucobalanus Eng.).

40. Q. chrysolepis Liebm. (Leucobalanus Eug., Lepidobalanus Det., sectio IV. Ilex Orst.).

41. Q. rugosa Née. (Lepidobalanus DeC.).

12. Q. Ilex nebst Fordii Hort. (Lepidobalanus DeC., sectio IV. Ilex Orst.).

43. Q. coccifera L. (Subg. III. Cerris, sectio IV, Ilicopsis Orst.). 44. Q. Calliprinos L. (Subg. Ill. Cerris, sectio IV. Ilicopsis Orst.). 45. Q. lanuginosa Don. (Subg. III. Cerris, sectio III. Suber Orst.). 46. Q. paucilammellosa Hook. (Subfam. I. Cyclobalanopsis Orst. Subg. I. Eucyclobalanopsis, sectiv I. Orst.).

47. Q. glabra Thunbg. (Sect. Pasania Miq., Subgen. I. Eupasania Orst., sectio I.).

48. Q. Burgeri Bl. (Subfam. I. Cyclobalanopsis Orst., Subg. I. Eucyclobalanopsis, sectio I. Orst.).

49. Q. gilva Bl. (Subfam. I. Cyclobalanopsis Orst., Subg. I. Eucyclobalanopsis, sectio I. Orst.).

50. Q. thalassica Hance (Sect. Pasania Miq, Subg. I. Eupasania Ørst., sectio I. Orst.).

Gruppe $\beta$ : Radiale Züge der Gefässe wie auch die Gruppen der letzteren meist schmal.

51. Q. Suber L. (Subg. III. Cerris Orst., sect. III. Suber Orst., Lepidobalanus DeC.).

52. Q. agrifolia Née. (Melanobalanus Eng., Subg. I. Lepidobalanus DeC., sectio IV. Ilex Orst.).

53. Q. glauca Thunb. (Subfam. I. Cyclobalanopsis Orst., Subg. I. Eucyclobalanopsis Øsrt., sectio I.

Mit spärlichen breiten Markstrahlen und radialer Anordnung der Holzspitzzellen:

54. Q. cuspidata Thunbg. (Pasania, Subg. II. Chlamydobalauus (Endl.) Orst.). 


\section{Hauptabtheilung B.}

Breite Markstrahlen erscheinen unter dem Mikroskop betrachtet durch dazwischentretende Holzzellen zu gruppenartig beisammenstehenden schmaleren Markstrahlen aufgelöst.

55. Q. dilatata Lindl. ${ }^{1}$ ) (Lepidobalanus DeC.).

(Ilieran dürften anch Q. rugosa Née. und Q. Ilex L. erinnern.)

Diese soeben gegebene Eintheilung der Eichen wird gewiss durch umfassendere Untersuchungen noch manche Abänderung erfahren. Dass diese Gruppirung ihre Berechtigung hat, und nicht auf blos zufälligen Nerkmalen beruht, lehrt mich der Vergleich mit den auf morphologisehen Merkmalen begründeten Systemen von Engelmann ${ }^{2}$ ) und Orsted ${ }^{3}$ ). Mit grosser Befriedigung ersah ich, dass die Abtheilung a in den Gruppen $\alpha-\gamma$ der Unterabtheilung I. Engelmann's Arten der Abtheilung Leucobalanus ("White.Oaks") ${ }^{4}$ ) Orsted's I. und II. Section des Subgen. I. Lepidobalanus DeC. zum Theil vollständig ${ }^{5}$ ) enthielten.

Zur Abtheilung a, Unterabtheilung II. mit den Gruppen $\alpha-\gamma$ gehören Engelmann's 2. Abtheilung Melanobalanus („Black-Oaks“) ${ }^{6}$ ) zum grössten Theil und Orsted's Subgen. III. Erythrobalanus mit den beiden ersten Sectionen Euerythrobalanus und Mikrokarpaea. Von letzterer ist nur Q. Wislizeni Alph. DeC. ausgenommen, welche sich bei mir unter a. I. $\alpha$. befindet. Die immergrïnen Eichen der Abtheilung b zeigen in ihrem anatomisehen Bau eine grosse Uebereinstimmung. Neben den Gefässen, die von ihrer normalen Stellung nur wenig abweichen, gewähren auch Anordnung der Holzstumpfzellen und Beschaffenheit breiter Markstrahlen für die einzelnen Hölzer wesent-

1) Anm.: Die Arten unter $6,13,22,26,35$ und $38-55$ sind immergrüne Eichen.

2) Engelmann: "Notes on oaks of the United-States".

3) $\theta$ rsted: Recherches sur la classification des Chênes (Extrait des mémoires de la Société ('Histoire Naturelle de Copenhague) 1867.

4) Taf. XII. Fig. 27 vrgl. Figurenerklärung.

5) Die Ausnahmen sind aus den in Klammern beigefügten, dem Artnamen nachfolgenden Abtheilungsbezeichuungen der Gruppenübersicht zu ersehen.

6) Taf. XII. Fig. 28 vrgl. Figurenerklärung. 
liche Merkmale. Ich erinnere nur an Quercus glauca und cuspidata. Lctztere steht eigentlich für sich da, aber die Anordnung ihrer Gefässe, sowie das Vorkommen breiter Markstrahlen nähert sie der Abtheilung b, obgleich in ihrem Stamm die radiale Anordnung der Holzspitzzellen mehr als aus anderen Eichenstämmen hervorleuchtet. Betrachtet man Querschnitte dieser Eiche, lie keine breite Markstrahlen aufweisen, so wird man lebhaft an clas Holz der Castanopsis indica Alph. DeC. erimnert. Den Stämmen der beiden Arten Castanopsis indica und C. chrysophylla fehlen breite Markstrahlen und die weitlichtigen Holzspitzzellen stehen in radialer Anordnung, die nur von den tangentialen Reihen und Gruppen der Holzstumpfzellen unterbrochen wird.

Durch die radialen schlängelnden Reihen seitlich etwas zusammengedrüekter Gefässe erinnert Castanopsis indica ${ }^{1}$ ) besonders an Quercus glauca, bei der aber dieselben enger sind. Castanopsis chrysophylla besitzt dünnwandige Gefässe zweierlei Art wie die Eichen der Abtheilung a. I. $\alpha$., doch stehen die weiten Gefüsse des Frühlingsholzes sehr vereinzelt und sind von einander tangential etwa $1 \mathrm{~mm}$ weit entfernt. Alles Uebrige wie bei $\mathrm{C}$. indica.

Zum Schluss mag hier eine Uebersicht ïber die wichtigsten anatomischen Unterschiedle des Eichenholzes gegenüber den verwandten Gattungen folgen:

IIt vorwiegend tangentialer Anordnung der Stumpfzellen im Herbstholz.

I. Nit breiten compacten oder von Holzzellen durchsetzten sowie kleinen schmalen Markstrahlen.

a) Mit Gefüssen zweierlei Art, von denen die weiteren zu concentrischen Kreisen im Frühlingsholz, die kleineren engen dagegen in radialer Anordnung im Herbstholz stehen, oder

b) mit Gefässen einerlei Art in radialen Reihen

Quercus.

1) Fig. 30 . 
II. Mit einförmigen, niedrigen, tangential nur 1-2 Zellen breiten Markstrahlen und Gefässarten wie bei I. (Holzspitzzellen mit radialer Anordnung)

$$
\begin{gathered}
\text { Castanopsis. } \\
\text { Castanea. }
\end{gathered}
$$

(Bei letzterer sind die Holzstumpfzellen zuweilen im Herbstholz sehr unregelmässig gelagert, aber eine tangentiale Anordnung ist stets zu erkemnen. ${ }^{1}$ )

\section{Erklïrung der Abbildungen.}

Tafel IX-XIl.

Fig. 1 a.b. c. l. Krystalle von oxalsaurem Kalk in den Stumpfzellen ron Quercus vireus Ait.

Fig. 2. Tangentialer Schnitt durch Quereus laurifolia zeigt den Theil eines breiteu Malkstrabls, in welchem sich einige Krystalle ron oxalsaurem Kali befinden. Einige Jlarkstrablzellen besitzen Poren $\mathrm{p}$, die auf Zellzwischenräume ansgehen.

Fig. 3. Markstralılzellen verschiedener Länge aus einem grossen Markstrah] von Quereus Phellos L.

Fig. 4. Zellen aus macerirten Markstrahlen von Quercus oblongifolia Torr.

a) Eine Reihe spitzer Markstrablzellen aus einem grossen Markstrahl.

b) Ungewöhulich hohe Markstrahlzellen ebendaher; str Stärkekörner.

Fig. 5. Ein Gefüss aus Quercus pedunculata Ehrb. an dem einen Ende doppelt durchbrochen.

Fig. 6. Ein ebenso gestaltetes Gefäss aus dem Stamme von Quercus oblongifolia Torr.

Fig. 7. Ein sehr hurzes, lang geschuäbeltes Gefäss von Quercus oblongifolia Torr.

Fig. 8. Ein unregelmässig gefeldertes Gefüss ans Quercus glabra Thunbg.

Fig. 9 Ein regelmässig gefeldertes Gefäss aus Quercus oblongifolia Torr.

Fig. 10. Ein leiterförmig geportes Gefäss aus Quercus lanuginosa Don.

Fig. 11. Ein leitertörnig durchbrochenes Gefäss aus Quercus cuspidata Thunug.

Fig. 12. Eine kugelige Thylle mit kegelförmigen Poren aus einem Gefäss von Querens stellata Wang.

1) J. Möller berichtigt l. c. p. 318 irrthümlich C. Sanio's Diagnose für das Holz von Castanea vesca. Wie ich mich überzeugt habe, fehlen letzterer Art weder Holzstumpfzellen noch Uebergangszellen (Tracheiden). C. Sanio's Diagnose $\mathrm{hp}+\mathrm{l}(\mathrm{t}+\mathrm{G})$ bleibt $\mathrm{zu}$ Recht bestehen. 
Fig. 13. Eine Thylle mit Stärkekörnern aus einem Gefäss von Quercus Kelloggii Newb.

Fig. 14 a. b., Gefässe, c. Uebergangszelle aus Quercus oblongifolia Torr.

Fig. 15 a. b. Uebergangszellen ans macerirtem Material von Quercus pedunculata Ehrh.

a stellt eine ganze Uebergangszelle dar 1:150.

b zeigt nur das eine Ende einer solchen Zelle vergrössert 1:450.

Fig. 16. Uebergangszellen neben Holzstumpfzellen mit seitlichen Fortsätzen. a bei Quercus Phellos L.

b bei Q. pedunculata Ehrl.

$\mathrm{u}=$ Uebergangszelle.

st $=$ Stumpfzelle.

Fig. 17. Gabelig getheiltes Ende einer Uebergangszelle aus Quercus lanuginosa Don.

Fig. 18 a. b. Holzspitzzellen mit gabelig getheiltem Ende

a aus Quercus pedunculata Ebrb.,

b - Quercus pedunculata Ehrh., die bei Frechem unweit Köln in angeblich römischen Bädern gefunden wurde. Das Zellende $a$ steckte in einem entsprechenden Loche $\beta$ des nebenan gezeichneten verbreiterten Endes einer anderen Holzspitzzelle.

Fig. 19. Dreigabeliges Ende einer Holzspitzzelle aus macerirtem Haterial von Quercus Kelloggii Nemb.

Fig. 20 Buchtig gezähntes Ende einer Holzspitzzelle mit senkrechten Spaltporen aus dem Stamme von Quercus lanuginosa Don.

Fig. 21 a. b. Holzspitzzellen aus Quercus Cerris I.

a Holzspitz- und Holzstumpfzelle von einem anstossenden Markstrahl gebogen.

b Doppelt gekniete Holzspitzzelle.

Fig. 22 a. b. Stumpfzellen aus Quercus Kelloggii Nenb.

a stellt zwei bei $v$ in Verbindung stebende Stumpfzellen st dar, die oben durch Markstrahlzellen $\mathrm{m}$ getrennt sind.

b Zwei Stumpfzellen, ron denen die untere $s_{2}$ seitliche Fortsätze zeigt.

Fig. 23. Eine Stumpfzelle mit seitlichen Fortsätzen aus Quercus cuspidata Thunbg.

Fig. 24 a. b. Aehnliche Stumpfzellen aus Quercus pedunculata Ehrh.

Fig. 24c. Zwei Stumpfzellen aus Quercus lyrata Walt. durch Fortsätze communicirend. Bei $d$ ist die eine der communicirenden Zellen allein dargestellt („Conjugirtes Parenchym" C. Sanio).

Fig. 25 Eine Stumpfzelle, die mit einem Gefäss durch elliptische Poren in Verbindung stand. Aus dem Stamm von Quercus linuginosa Don.

Fig. 26 Holmspitzzellen aus Qnercus oblongifolia Torr an den Enden umeinander gedrebt.

Fig. 27. Querschnitt von Quercus alba L. stellt dar den Theil eines Jahresringes $z$ wischen $z$ wei grossen Harkstrahlen $\mathbf{M I}$. Oben bei grenzt der Jahresring an den nächst jüngeren, der auf der Zeichnung fehlt und unten bei $b$ an den nächst älteren, der ebenfalls nicht gezeichnet ist.

G: Grosse Gefässe des Frühlingsholzes, ungeben von weitlichtigen Uebergangs-, Holzspitz- und einigen Holzstumpfzelleu. Die meisten grossen Gefässe enthalten Thrilen. 
gr: Kleine Gelïsse des Ilerbstholzes im mittleren l'lheile des Jahresringes in schmalen radialen Zügen angeordnet, welche gegen das Herbstholz an Breite zunehmen und an der Grenze des letzteren bei $\mathrm{g}^{\prime}$ zur Vereinigung gelangen. Ihre Ungebung wird aus denselben Zellarten gebildet wie die der grossen Gefässe.

$\mathrm{h}$ : Holzspitzzellen werden nur angedeutet und bilden die helleren Stellen ¿wischen den radialen Zügen kleiner Gefüsse.

st: Holzstumpfzellen in bogig verlanfenden tangentialen keihen, die zuweilen kïrzer, zuwcilen länger sind.

$\mathrm{m}$ : Kleine Markstrahlen zwisehen den grossen Gefïssen bogig verlanfend.

Aumerkung: Quereus alba mit den diehistehenden engenkleinen Gefässen im Herbstholz veranschaulicht den inneren Bau der amerikanischen "White-Oaks"am besten.

Fig. 28. Querschnitt von Quereus Phellos L. stellt den Theil eines Jahresringes zwischen zwei grossen Markstrahlen MM' dar.

$\mathrm{a}$ und $\mathrm{b}$ wie in voriger Figur.

G: Grosse Gefässe des Frühlingsholzes. Dieselben lassen bereits eine Gruppirumg erkennen.

g: Eleine Gefässe bilden lange schmale Reihen und radial gestreelste Gruppen gr. Die kleinen Gefïsse sind hier weiter als bei voriger Art und stehen in den Reihen radial weiter ron einander ab. Sie werden ebenfalls wie die grossen Gefässe von Uebergangs- und Stumpfzellen umgeben.

$h$ wie in voriger Figur.

st: Holzstumpfzellen in meist maschenartiger Anordnung oder in vereinzelten Gruppen. Die tangentiale Anordnung derselben gelangt hier nicht zum Ausdruek. m: Kleine Markstrahlen.

Anmerkung: Quercus Phellos gehört den "Black-Oaks" an und unterseheidet sich von den.,White-Oaks"besonders durch dieweiten entfernt stehenden kleinen Gefäse. Q. Phellos repritisentirt den Typus der "Black-0aks".

Fig. 29. Querschnitt von Quereus dilatata Lindl.

$\mathrm{Mg} \mathrm{Jg}{ }$ : Gruppen von 2-4 Zellen breiten Harkstrahlen an Stellen von gewöhnlichen breiten Markstrahlen.

G: Gefässe einerlei Weite wie bei den meisten immergrünen Eiehen. Ihre Gruppen sind zerstreut und zeigen eine radiale Anordnung nur schwach.

$\mathrm{G}^{4}$ : Ein Gefäss in der Markstrahlgruppe $\mathrm{Mg}$.

Gt: Ein Gefäss mit Thyllen.

$\mathrm{h}$, st und $\mathrm{m}$ : wie in Fig. 27.

Fig. 30. Querschnitt von Castanopsis indica Alph. DeC.

G: Gefäss, tangential zusammengedrückt.

Gz: Ein radialer Gefässzug, der einen bogigen oder geschlängelten Verlauf zeigt.

Gg: Eine Gruppe radial angeordneter Gefässe.

$\mathrm{h}$ : wie in voriger Figur.

st': Stumpfzellen in tangentialen Reihen angeordnet.

st": Stumpfzellen in maschenartiger Anordnung.

m: Kleine Markstrahlen, wie sie anch bei Castanopsis chrysophylla Alph. DeC. und Castanea vesca Gärtn. vorkommen. 



\section{Thesen.}

I.

Bastarde und spielarten düren nicht mit Artnamen bezeichnet werlen.

II.

spiclarten sind durch Kreuzung zu cutscheiden.

III.

Was Vater oder Mutter bei einer Krenzung zweier Pllanzenarten gewesen ist, kamn man den spontanen Batstarlen nicht ansehen. 


\section{Vita.}

Ego, Juhannes Abromeit, natus sum a. d. XIII. Cal. Mart. MDCCCLVII in vico P'aschleitschen prope Ragnit, quod est oppidulum Borussiae orientalis,' sito, patre Johanne, matre Emilia c gente Motejat, quam jam pridem milhi ereptam doleo. Confessioni evangeliea addictus sum. Annos XIV natus per quinquennium ProReal-Gymnasiun Gumbinnense frequentavi, unde anno HDCCCLXXYII Regiomontium me contuli, ubi in Real-Gymnasium, quod appellatur: in arce, receptus sum. Ibi per duos amos literis propaedenticis incubui et testimonio maturitatis adepto anno IDCCCLXXIX primo vere almam Albertinam petii et numero academicorum rite adscriptus per novem semestria studiis rerum naturae operam dedi atque scholis interfui virorum doctissimorum optime de me meritorum:

Baner, Baumgart, Blochmann, R. Caspary, Hertwig, Jentzsch, Lossen, Pape, Quaebicker $\dagger$, Ritthausen, Walter, v. Wittich, Zaddach $†$.

Quibus omnibus viris illustrissimis, valde venerandis, gratias ago quam maximas. Plurima autem debeo praeclarissimo viro R. Caspary, qui non solum ad hoc opusculum conscribendum me incitavit, sed etian instrumentis mieroscopicis suis me benignissime adjuvit. 
9391 



